\title{
مفهوم الإتيقا في فلسفة "إيمانويل ليفينس"
}

$$
\text { تالصفا علي القيل }
$$

د. / دعاء وجدى محمد ***

أ.د / وفاء محمد أحمد إبراهيم**

المستخلص

يعرف " ليفينس" بأنه فيلسوف اتيقا الغيرية وفيلسوف الوجه، فلقد ظل " ليفينس" طو ال حياته

الفكرية ينادي بأن تكون الاتيقا هى الفلسفة الأولى، هذه الاتيقا تعتمد على التوجه نحو الآخر الإنساني

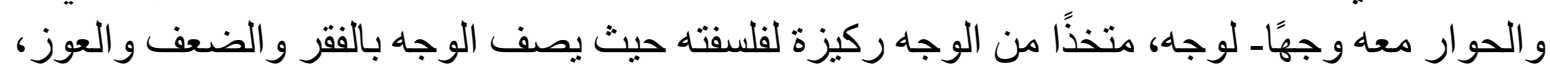

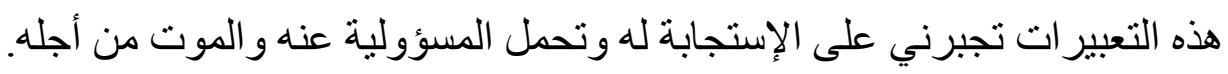

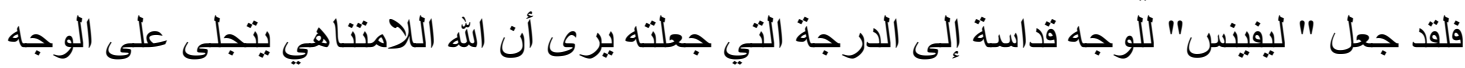

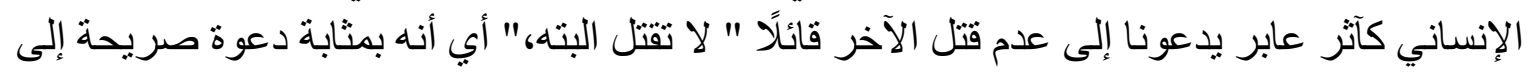

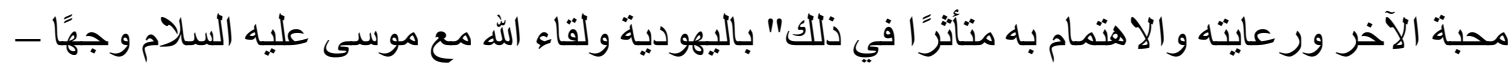

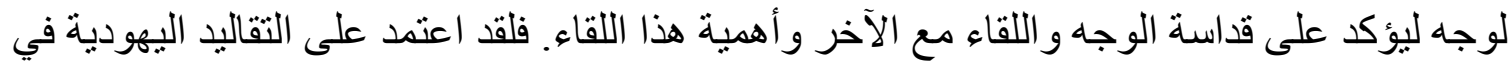
صياغة اتيقاه بعد فثل الأخلاق من وجهة نظره في أحداث الهولوكست. فرفض كل الوذاء الهذ اهب الأخلافية

$$
\text { وصاغ اتيقا الوجهاه. }
$$

الكلمات المفتاحية: الوجه، اللانهائي،المسؤولية، الإنفصال، الخضوع و التبعية مقدمة البحث:

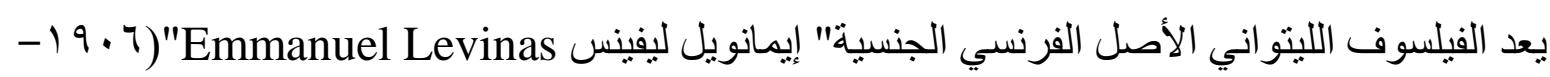

99 ( 99 أحد أهم فلاسفة القرن العشرين،حيث ساهم في نقل التيار الفينومينولوجي من ألمانيا إلى فرنسا. فكانت فلسفته بمثابة ثورة على التراث الفلسفي الغربي الذي اهتم بمقولات العقل والمنطق والسؤال عن الوجود وعن الذات وعلاقتها بالموضوع، ، فلقد رفض " ليفينس" هذا التراث لأنه أهمل السؤال عن الآخر الإنساني وعلاقته بالآخر . 
وتكمن أهمية " ليفينس" الفلسفية في أنه سعى إلى تحرير نفسه من الفلسفة الدفتونة بمسألة الوجود

والسؤال عن وجود الأثياء والعالم، والفلسفة الكليانية التي هيمنت على الفلسفة الغربية منصرفًا إلى إلى الاهتمام بالاتيقا بوصفها الفلسفة الأولى وأنها ليست فرعًا من فروع الفلسفة، فهو يرفض الأخلاق التقليدية

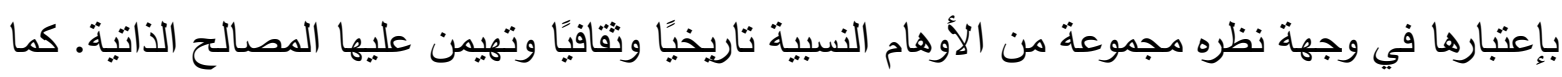
أنها ليست أخلاق الواجب التي تعتمد على العقلانية في التنظيم الإجتماعي للسلوك الإنساني والضرورة

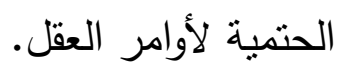

وتعتدد الاتيقا عنده على اللقاء مع الآخر الإنساني من خلال الوجه الإنساني حيث يتجلى الله

على الوجه قائلًا " لا تقتل" والتي هى أحد الوصايا العشر في الديانة اليهودية، فيتجلى الله كآثر داعيًا

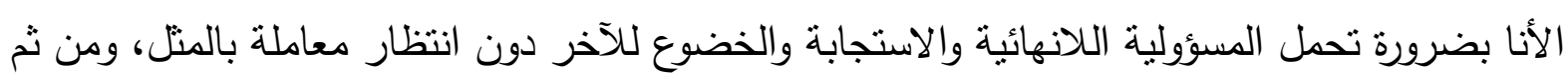

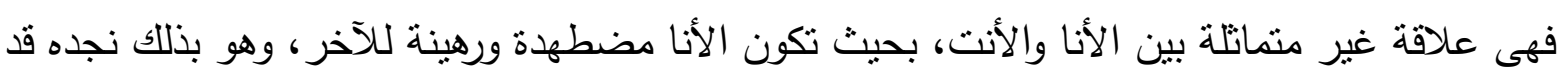

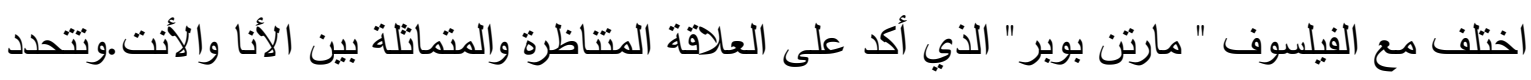
هوية الذات عند " ليفين" من خلال استجابتها للآخر وخضوعها له وليس من خلال أفعالها الحرة التي

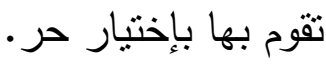

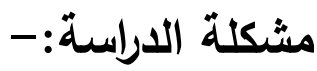

جاءت الدراسة لطرح العديد من الإثكاليات والتساؤلات التي تتعلق بالاتيقا والوجه، منها. 1- ماذا يقصد " ليفينس" بالوجه؟ وما الدور الذي يلعبه في فلسفته؟

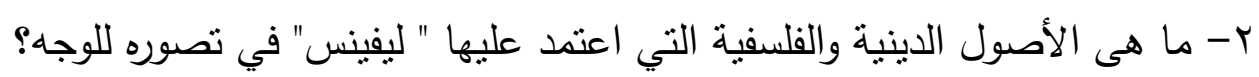
r- ما الدور الذي يلعبه اللانهائي في الاتيقا؟ ع - هل المسؤولية نحو الآخر تفضي إلى العبودية عند" ليفينس"؟ وما الفرق بين المسؤولية عند " سارتر"

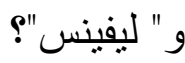
0- هل يوجد معنى حقيقي للذاتية عند" ليفينس"؟ 1- هل هناك معنى حقيقي للحرية في فلسفة " ليفينس" الاتيقية؟ V- كيف تصور" ليفينس" الموت؟ وما هى أوجه نقده لتصور "هيدجر" للموت؟ هئ 
- - تهدف الدراسة إلى توضيح أهمية وقداسة الوجه عند " ليفين" ودوره في تأسيس المشروع الاتيقي. - التأكيد على أهمية اللقاء مع الآخر الإنساني وضرورة العيش الجيد مع الآخر ورعايته.

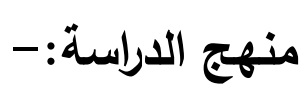
افترضت طبيعة الموضوع وتتوع مادته استخدام الدنهج ( التحليلي والنقدي، المقارن).

\section{أولاً : دلالة الوجه The Face:}

يلعب مفهوم الوجه دورًا محوريًا في فلسفة " ليفينس Levinas" وهو الدفهوم الأساسي والخاص به، وقد استتدت عليه كل المفاهيم والتصورات الفلسفية والاتيقية الآخرى لديه. ونظرًا لأهية هذا المفهوم سوف توضحه الباحثة من خلال بعض التساؤلات وهى: ماذا يقصد " ليفينس" بالوجه؟ وما الدنهج الذي اعتمد عليه في تحليله للوجه؟ وما هى الأصول أو المصادر التي اعتمدها عليها لتدعيم آراءه عن الوجه؟ بهن

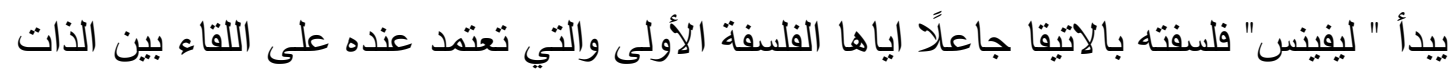
والآخر • هذا اللقاء ينم من خلال الوجه. فهو يرى أن " الوجه يعبر عن الحضور والظهور، ويحدد هوية

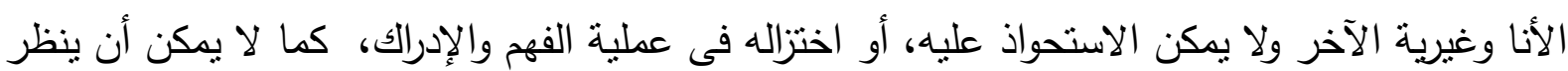

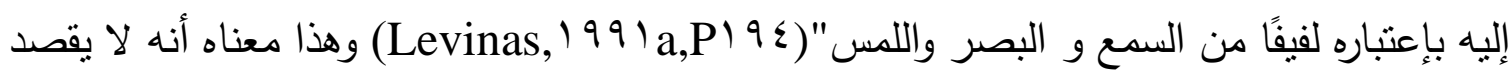
بالوجه ملامح وهيئة الثخص أو كونه قبيحًا أو جميلًا، وإنما يقصد رؤية الكائن بمجمله، فالوجه هو تتخيص للإنسان الآخر ككل، وليس الجانب الجسدي له.إنه الكثف عن غيرية الآخر .

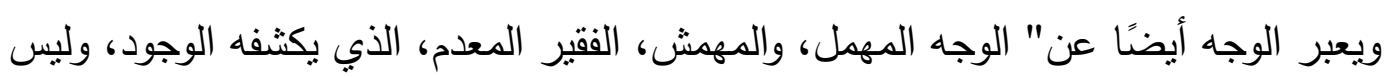

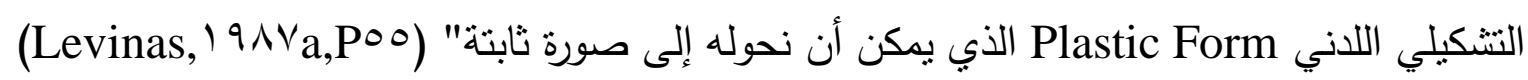
وهذا يعني أن الوجه هو رؤية التعبيرات التي تتجلى عليه. وبناء على ذلك " لا ينظر للوجه بطريقة

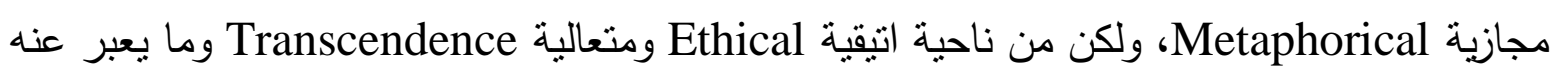
لا يتعلق بشخص معين، بل يتعلق بالعلاقة مع الثخص الآخر ، بعبارة آخرى الوجه له دلالة اتيقية تؤكد

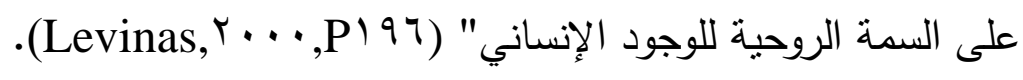




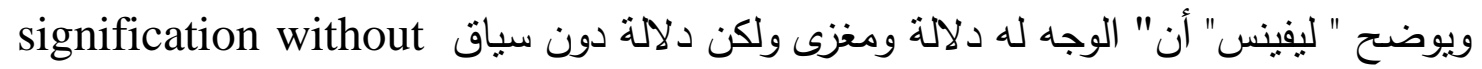
context أو المعنى يجعلنا نهرب من الوجود إلى الاتيقا، فالعلاقة مع الوجه هى علاقة اتيقية، فالوجه مالا يمكن

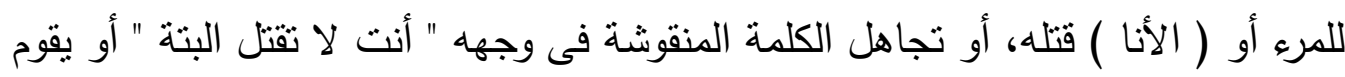

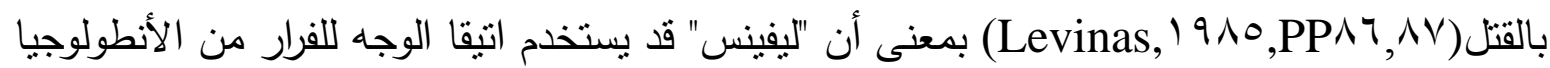

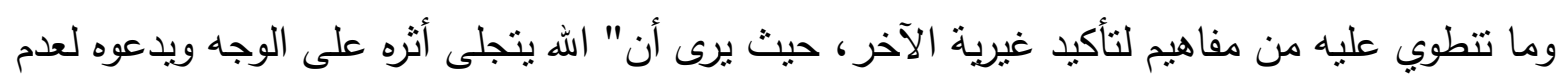
قتل الآخر ورعايته والإهتمام به.

وهذا الآثز Trace بحد ذاته هو الذي يجعلني مسؤولًا عن الآخر واتحمل كل أخطائه وجرائمه، بل

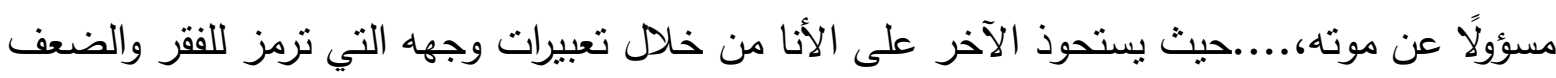

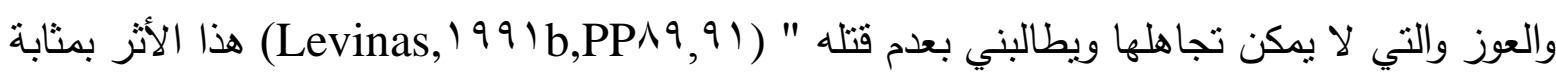
صحوة للأنا للتوجه نحو الآخر والقرب والدنو منه.

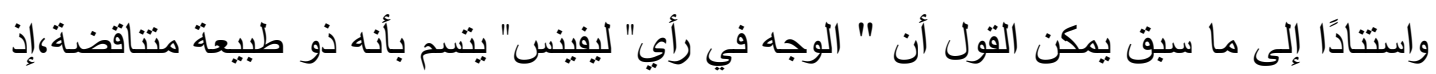

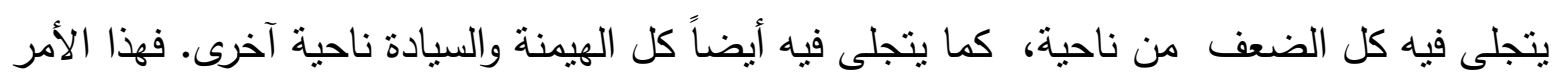

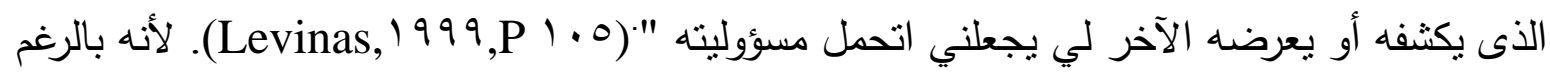
من ضعف الوجه وهشاشته يتجلى الله على الوجه فيجعله قوي وله سلطة فيحظر القتل، وهذا ما أكده " ليفينس" بأن" ما يميز الوجه الإنسانى عن وجه الحيوان هو الهثاشة والضعف المطلق الذى يتسم به لهانه الوجه الإنسانى وأيضا السلطة والتى تظهر عندما يتجلى الله على وجه الآخر ـ فالوجه يعبر عن هشاشة

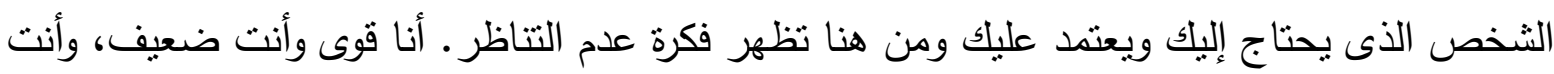

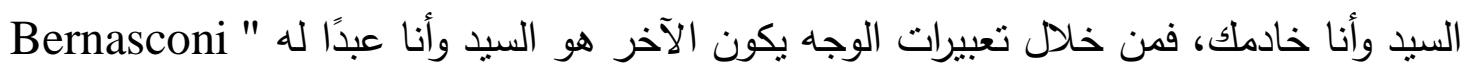
.(\&Wood, 19^^,PP $17 \wedge, 1 \vee \cdot)$

وبهذا يكون الوجه هو مصدر الإلزام الاتيقي وليس قوانين العقل والمنطق، لأن الوجه يتجاوز أي

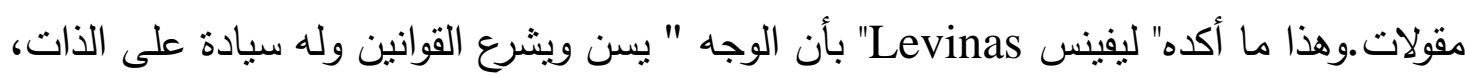

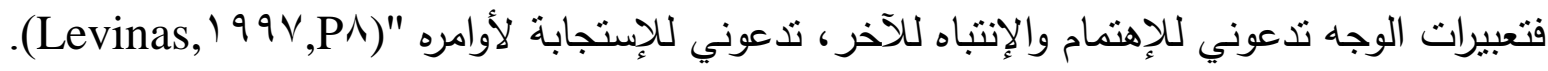


أما عن المنهج الذي استخدمه في تحليله للوجه فهو المنهج الفينومينولوجي بإعتماده على القصدية

والتوجه نحو الآخر كقصد وهدف كذلك اعتماده على الوصف الفينومينولوجي، وهنا قد نجد نثابه بين الوصف الفينومينولوجي للوجه عند " ليفينس" والوصف الفينومينولوجي لهيدجر في تحليله للوحة فان غوغ والخاصة بحذاء الفلاحي* التي تكثف الفقر المقدد والبؤس وجدير بالذكر أن " ليفينس" قد تجاوز الفينومينولوجيا لأنها" بالنسبة له تفشل في تصور اللقاء مع

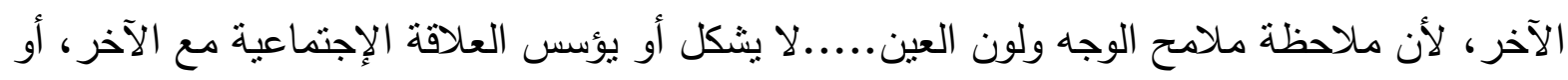
تأكيد غيرية الآخر " (Levinas, 1910,P^0) أما عن المصادر التي اعتمد عليها " ليفينس" في تصوره للوجه، فيأتي في مقدمتها الكتاب المقدس فقد استقى منه فكرة الوجه وبنى عليها فلسفته، بالإضافة إلى اعتماده على بعض الهصادر الفلسفية

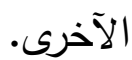

يستتد" ليفينس" إلى الكتاب المقس لتوضيح قداسة الوجه، فنجده يعود إلى سفر التكوين (1: ب ب )

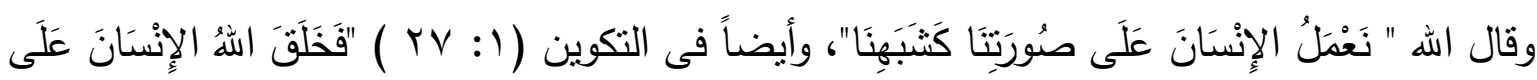

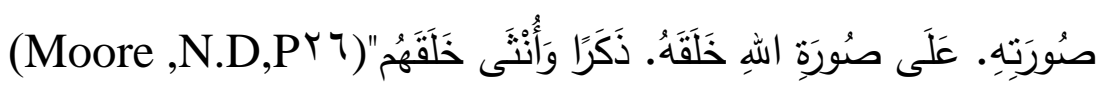

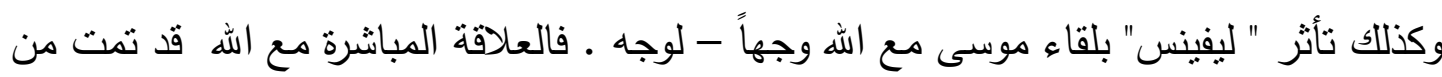

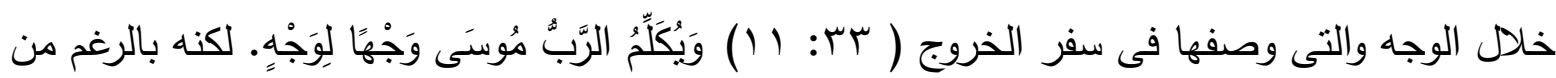

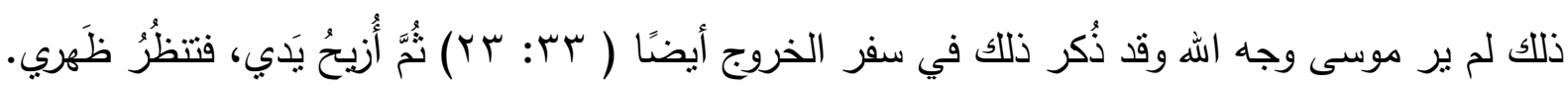
وأما وجهي، فلا تراهُ ـ أنه لقاء مع الله والذى هو فى ذات الوقت دنو وقرب من دون

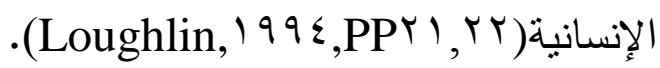

ويقر " ليفينس" بأن الكتاب المقدس له عدة مستويات وجوانب اتيقية. منها ما يؤكد على أهية الآخر ، وأنكك سوف تكافىء على الأفعال الاتثقية التي تقوم بها تجاهه، كذلك نجد فكرة القداسة فى الكتاب " هذا الحذاء الفلاحي نلاحظ فيه عناء خطوات العمل، فلقد تراكت في ثقل الحذاء الخشن الكتقن الصنع صرامة العملية

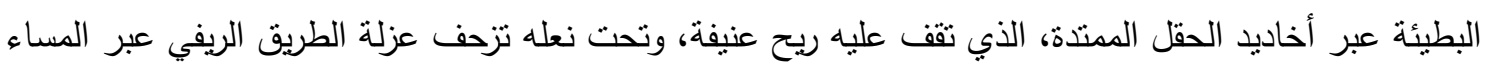

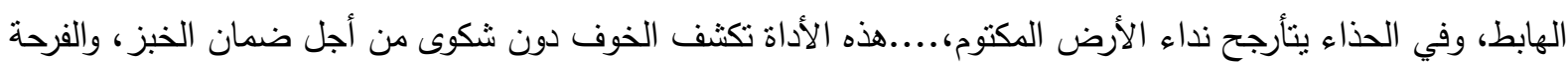

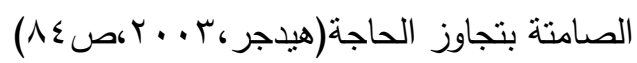


المقدس التي تؤكد على حضور الآخر وضرورة بقاءه ـ ففى العهد القديم نجد الوصية السادسة " أنت لا تقتل " ويجب أن تحب جارك ، يجب أن تحب الغريب ـ فروح الكتاب المقد تهتم بالضعيف ، والإلتزام

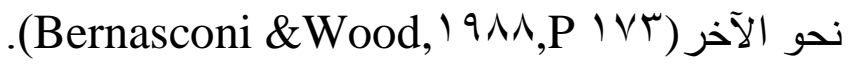

وعلاوة على ذلك يشير " ليفين" إلى أن الكتاب المقس ملىء بالأوامر والوصايا الكتابية التي

تؤكد على ضرورة استجابة الأنا لأوامر الأخر ، كما أنه يجسد العلاقة الاتقية بين الأنا والآخر ويؤكد على تحمل المسؤولية اللانهائية عنه، إذ يعلمنا الكتاب المقس أن الإنسان هو الذي يحب جاره، وحبه

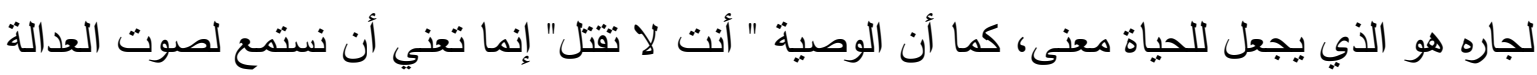
الإجتماعية Social Justice وهذا النداء قادمًا من الله، فلا تقتل ليست مجرد قاعدة بسيطة، إنما هى

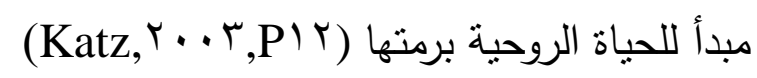

مما سبق بمكن القول أن " ليفينس" قد انغمس في اليهودية والتعاليم اليهودية بشكل كبير لصياغة

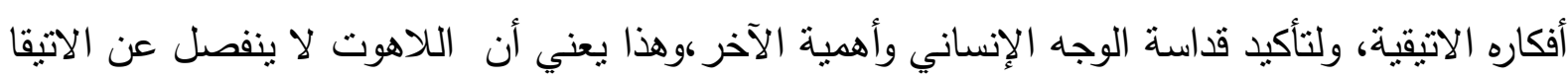

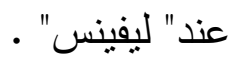

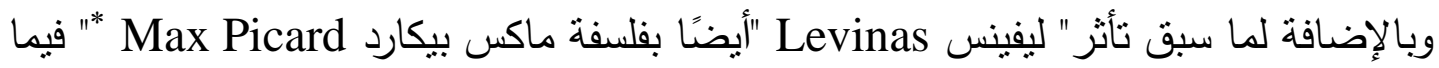
يتعلق بإهتمامها بالوجه الإنسانى وقدم " ليفينس" مقالًا عن فلسفة الوجه عند" بيكارد" في مؤلفه" أسماء علم" حيث تعد فلسفة الوجه philosophy of the face فكرة جوهرية فى فلسفة " بيكارد" ، فالوجه يعبر عن الثخصية ولكن فى ظهوره ووضوحه، وتجسده، وترحيبه، فالوجه هو سر كل الوضوح والانفتاح والاتصال مع الآخريين، كما يستخدم "بيكارد" التعبير الكتابى المقد، "الإنسان مخلوق فى صورة الله "، * ماكس بيكارد( (1) 1 - 1970) ولد في شوفهايم، وتوفي في سورونجو في سويسرا، انهى دراسته في الطب وحصل

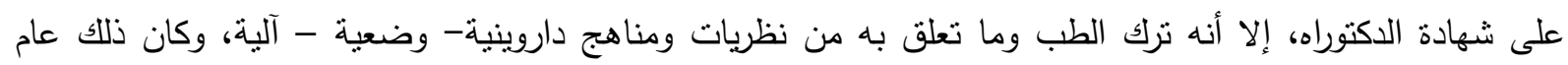

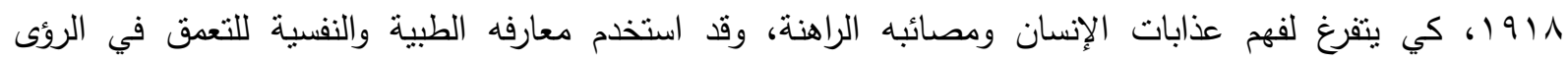

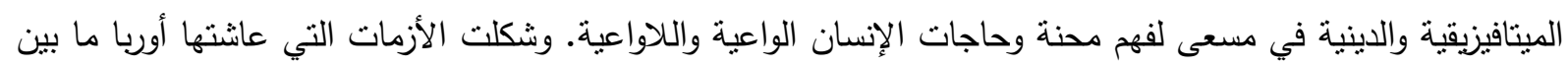

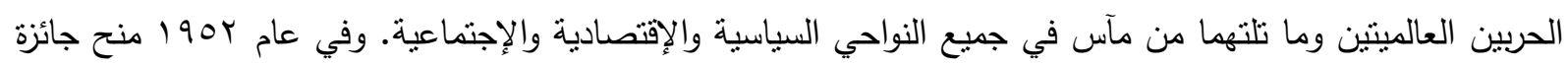

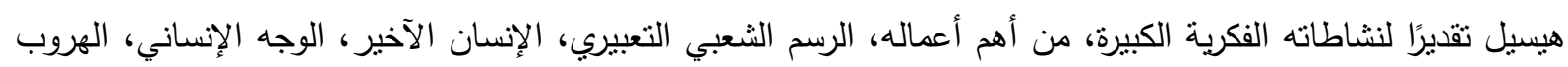
من الله، هنلر في نفوسنا

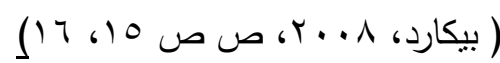


the فوجه الإنسان هو الدليل على وجود الله، كما يقول " بيكارد " إذ أنه يؤكد أن التوحيد الإلهى monotheistic divine الإنساني(Levinas, 1997 a,P 90). وقد نجد هنا اتفاقًا تامًا بين " بيكارد" و" ليفينس" في النأثر بالكتاب المقدس و التأكيد على ظهور وتجلي الله في الوجه الإنساني وأن الإنسان مخلوق على صورة الله. كذللك يرى " بيكارد" "أن الوجه الإنساني يعبر عن الحدود الفاصلة بين الصدت والكلام، أنه الجدار الذي تتبعث منه اللغة، في منل هذا الوجه، التجارب التي مر بها والتي تكون جميعها محفورة بعدق، فلا يوجد صمت في الوجه، فالكلمة لم تعد مغطاة بالصمت قبل خروجها من الفم: كل الكلمات تكون موجودة

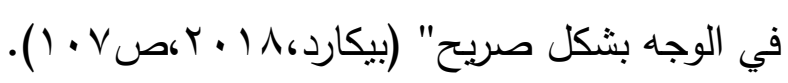
وهنا نجد اتفاق بين " ليفينس" و" بيكارد" على أن الوجه يتحدث ويخاطب الأنا.هذا الخطاب اتيقي

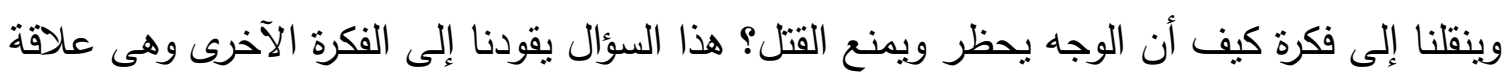
الوجه باللانهائي ( الله)

\section{ثانيًا: الوجه والنلانهائي The Face And Infinity:-}

يقترن مفهوم الوجه عند " ليفينس Levinas" باللانهائي حيث لا بمكن تناول أحدهما دون الآخر ، فتجلي اللانهائي على الوجه هو الذي يجعل له قداسة ويحقق الاتيقا التي تدعو للإستجابة للآخر ورعايته ويحظر القتل، وهو الذي يجعل له سلطة. ولأجل ذلك سوف نوضح الباحثة في هذا الجزء، كيف يرتبط الوجه باللانهائي؟ وهل اختلف تصور " ليفين" للانهائي عن تصور " ديكارت؟

يذهب " ليفينس" إلى أن وجه الآخر ينقلنا إلى فكرة اللانهائي والتي تمثل نقطة محورية للاتيقا

الميتافيزيقية لديه، فهو يرى أن فكرة اللانهائي تسمو على الذات التي تمتلكها، وأن الوصول إلى هذا اللانهائي يكون من خلال اللقاء الاتيقي مع الثخص الآخر الذي يدعونا وينادي علينا ويستدعينا دائمًا

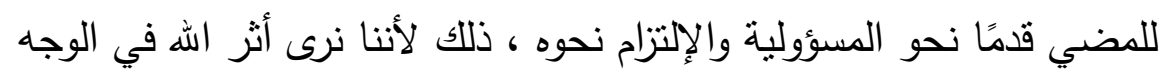

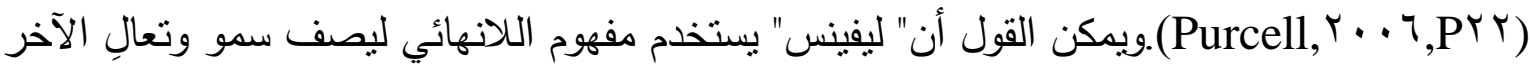
Height Of The Other ، وذللك لأن اللانهائي يحطم الدائرة المغلقة للكليانية ويتجه نحو

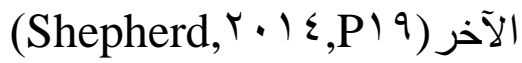


وقد استعان"ليفينس" بهذه الفكرة من ديكارت ليؤكد على عدم اختزال الآخر في النفس، فلقد رفض وجهات النظر النقليدية التي تبدأ بمعرفة الذات والتني من خلالها نستطيع معرفة الأثياء المحيطة بنا. أما بالنسبة له الآخر واللانهائي هم أساس علاقتتا بالأثياء بل أن معرفة اله تكون من خلال الآخر. كذلك برى " ليفينس" أن " العلاقة مع اللانهائي ليست مجرد علاقة معرفية أو تأملية وإنما هى لهى

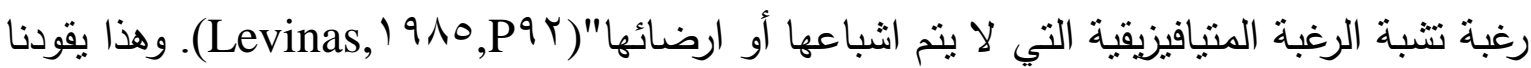
إلى توضيح الفرق والاختلاف بين الحاجة والرغبة عند " ليفينس".

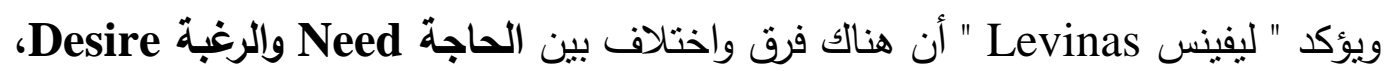
فالحاجة حركة داخلية Interiority وبيولوجية، بينما الرغبة هى علاقة مع السمو Height والخارجي Exteriority

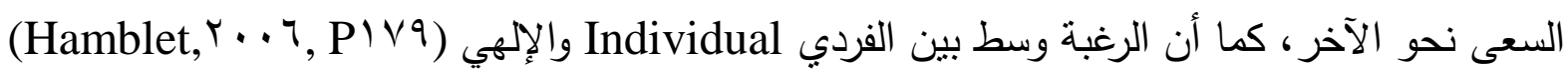

.Divine

وتتطوي الحاجة على فكرة الإفتقار ، أى الإفتقار إلى شىء أو نقص شىء معين، ويتم إرضائه

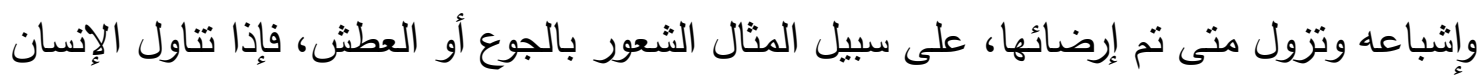
الطعام أو شرب الماء زالت الحاجة ـ (تبدأ من الذات، وتعود أيضاً إلى الذات) فيقول" ليفينس" " يتغذى الهی

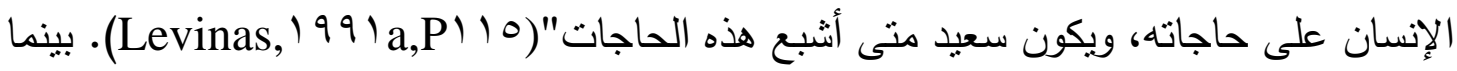

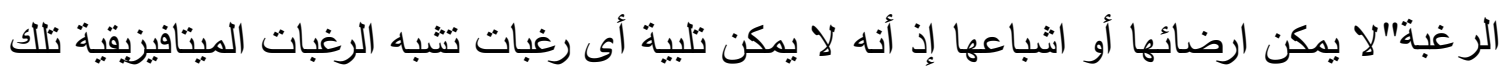
الرغبات التي تتجاوز كل ما يمكن ارضائه أو اكتماله ببساطة، متل الخيرية Goodness، الغيرية Alterity"(Ibid,P ع (I) بناء على ما سبق يمكن القول أن الرغبة تعني التطلع للاتصال بالمتعالي، وتستتد على اللقاء مع الآخر ،ولا يمكن اثباعها أو ارضاءها، فهى رغبة ميتافيزيقية تتجاوز كل ما يمكن اكماله. وتمانل

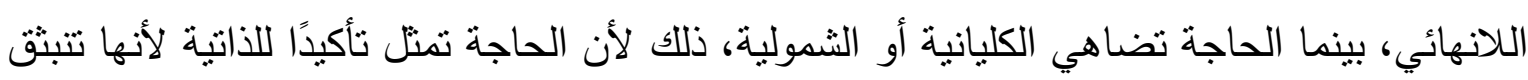

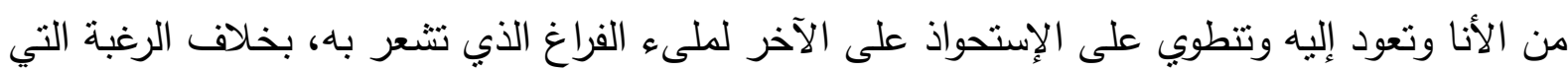

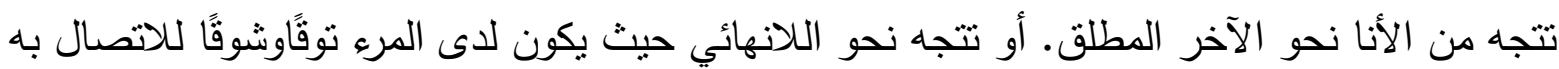
ويكون ذلك من خلا اللقاء الاتيقي مع الآخر وجهًا لوجه. 
يمكن القول أن اللانهائي عند " ليفين" يعبر عن العلاقة الإجتماعية التي تتمنل في الوجود الخارجاني على نحو مطلق Absolutely Exterior Being ( أى الوجه) والذي يكثف شكل المقاومة الاتيقية من خلا تعبيراته التي تقاوم استبداد الأنا، حيث يتعرض الآخر لكل أنشكال العنف والسيطرة من لهن

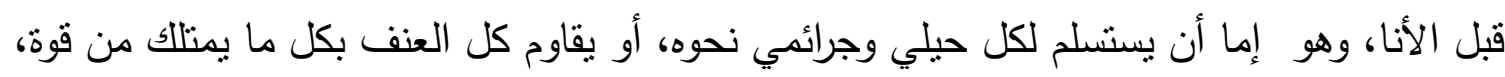
فالآخر يقدم نفسه لي من خلال الضعف الكلي الذي يتجلى عليه ونظرات عينيه الضعيفة التي يظهر فيها

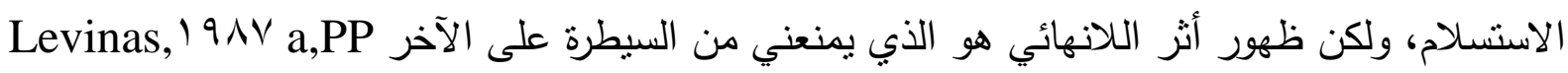
.$(0 \leqslant, 00)$ وهنا تكمن أهمية اللانهائي عند "ليفين" في أنه يمنع الهيمنة والسيطرة على الآخر ، ويحافظ على

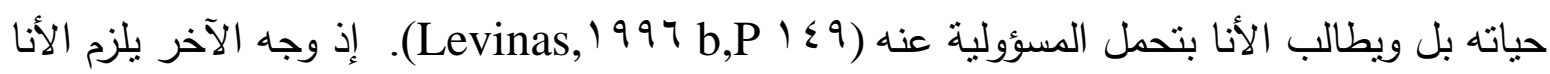
أن تنتجيب لكل أوامره ، حيث ينطوي الوجه على العديد من التعبيرات التي تتجلى عليه، ومن هذه

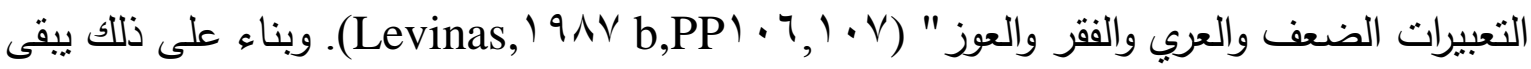
الآخر متعاِل بشكل لانهائي وعلاقتي معه لا تكون عنيفة وإنما بِودها السلام في ضوء هذه الغيرية

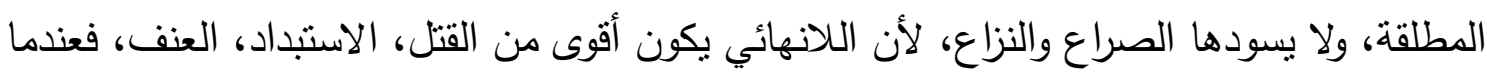
يتجلى اللانهائي على الوجه فأنه يجعل الأنا تستسلم للآخر وتستجيب لأوامره دون أب مقاومة

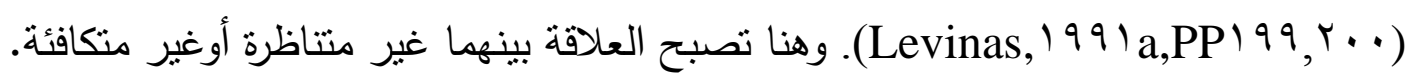
مما سبق يمكن القول، أن " ليفينس" قد فهم اللانهائي على نحو اتيقي وليس ابستيمولوجي معرفي كما هو الحال عند " ديكارت" فجمع " ليفينس" بين تصور "ديكارت"للانهائي وبين الرغبة نحو الخير

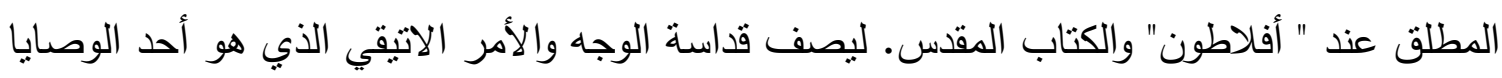
العشر في اليهودية. حيث يفترض " ليفين" أن "علاقتي مع اله تظهر في علاقتي مع الآخر ، وهذا ليس مجازًا أو استعارة، فهنالك حضور حقيقي لله في وجه الآخر ، فقي علاقتي مع الآخر اسمع كلمة الله" (Levinas, l9 9^a,P ll•) اشعيامه"'"أن القرب من الله والإخلاص نفسه، هو اخلاص إلى الإنسان

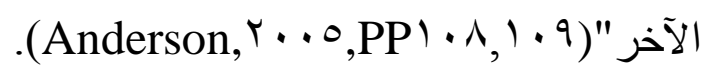


وتبعًا ل" ليفينس" فإن" هذا اللانهائي يمكن أن نسميه "الهه" أو "الخير الأقصى" أو "الرغبة"، بمعنى أنه لا يظهر لي كثىء معروف، ولكنه يمنل لحظة إلهام - وحي Inspiration تمر على وجه الآخر ، فاله لا يمكن معرفته، لكنه هو الذي يجعلني مسؤولاً عن الآخر ، فأنا لا أقابل الآخر كمحاور Trace In The ولكنه دائمًا متخفيًا لأن اللانهائي يتجلى كأثر في وجه الثخص الآخر Interlocutor Face Of The Other Person لوجه ليس مع الآخر وإنما مع اللانهائي أو اله الذي يأمرني بالإلتزام نحو الآخر والاستجابة لنداءه، فأن

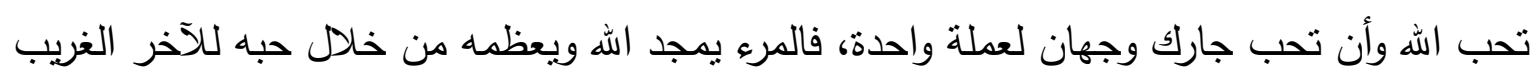

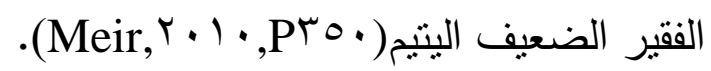

ويختتم " ليفينس" كلامه بأن " اللانهائي أو اله لبس هو إله الأنتوثيولوجي Onto-Theology، وإنما هو بالآحرى الحركة التي تتجاوز الوجود Beyond Being والتي تتحقق من خلال تجربة الوجه، فاله لا يوجد في الوجود السامي Heigher Being ولكن في العلاقة مع الآخر ، بعبارة آخرى، يتم

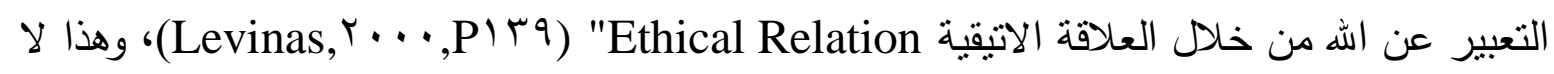
يعني أنه قد جعل اله على قدم المساواه مع الآخر ، ولكنه يجعل الحديث عن الله ممكنًا من خلال الحديث عن الآخر في العلاقة الاتيقية وأن الآخر يسمو على الذات نظرًا لتجلي أثنر الهه عليه. ثالثًا:اللقاء الاتيقي بين الأنا والآخر :اهتم " ليفينس Levinas" بلقاء الأنا والآخر وجهًا- لوجه، وقد تأثر بمارتن بوبر في تأكيده على

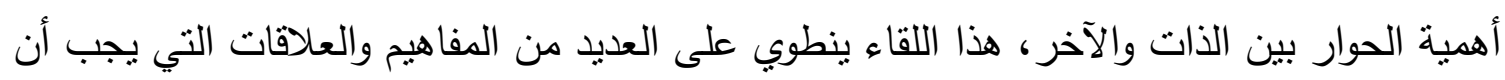
تتضمن فيه حتى يكون لقاء اتيقي يهتم برعاية الآخر واستمراره. من المكن أن نطرح عدة نساؤلات لتوضيح هذا اللقاء من خلال طرح بعض التساؤلات منها: هل انفصال Separation

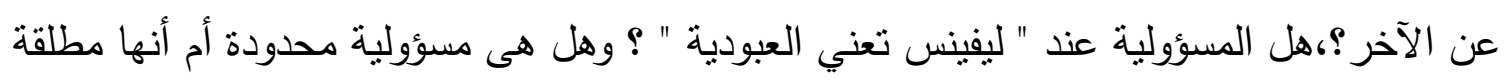

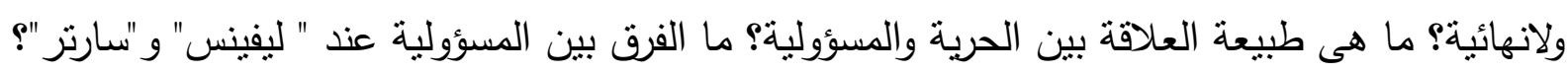
وأيهما كان أكثر صوابًا وأقرب للمنطق من الآخر؟ هل الذات في فلسفة " ليفينس" لها هوية أي تتسم 
بالحرية والاستقلال ؟ وما المقصود بمفهوم الاستعاضة Substitution ؟ ما الفرق بين اللقاء الاتيقي بين الأنا والآخر عند كل من " ليفينس" و "مارتن بوبر"؟

\section{1- الإنفصال Separation كضرورة للقاء الأنا مع الآخز:}

يؤكد " ليفين" أنه لضمان بقاء أو وجود كلاً من الأنا والآخر ينبغى أن يكون هناك إنفصال

بينهما. فهذا الانفصال يمنع حدوث ذوبان لأي منهما، بحيث يظل وجود الآخر وجودًا مستقلاً عن وجود

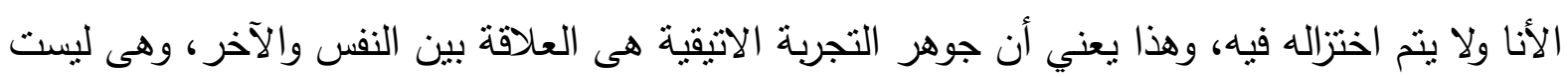
علاقة داخل النفس، وإنما هى علاقة تتجاوز الذات أى تكون خارج النفس وتتجه نحو الآخر . ويرى " ليفينس Levinas" أن هذه الذات المنفصلة ليست مرهونة بالآخر ، وإنما هى تتفتح نحوه

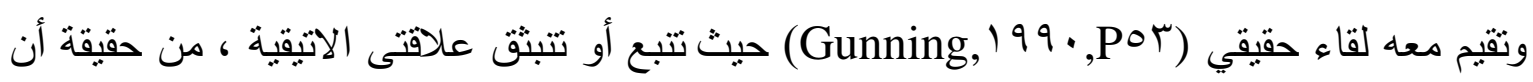
الذات لا يمكنها البقاء أو العيش بمفردها ، ولا يمكن أن تجد معناها فى الوجود فى العالم دون لقاء

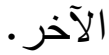

وهذا يؤكد أن" الاتيقا تتطلب الإنفصال، وذلك من أجل الثخص الآخر ، الذي يكون حرًا عندما يكون منفصلً عني بعيدًا عن إرادتي الجسدية والعقلية"(Levinas, 199 lb,POr). " ونستند فكرة الإنفصال هذه على فكرة الداخلية أو الجوانية Levinas 199 \a,P lV) "Interiority). التي يوضحها

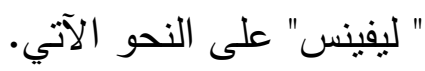

ولتوضيح مفهوم " الإنفصال" يستعين " ليفينس" بقصة راعي " ليديا " في محاورة الجمهورية

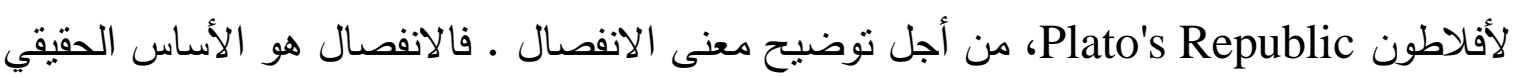
للقاء الذات والآخر • حيث في هذه القصة يرمز خاتم جيجس إلى الانفصال،فعندما برتدي الراعي الخاتم

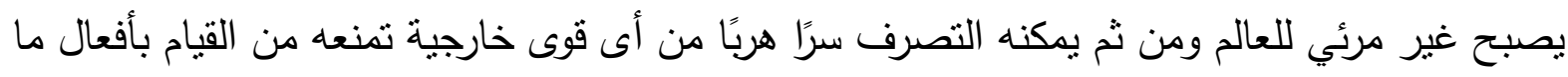
ويكون بالتالي منفصلًا عن الخارج (Gunning, 199 (Gor).

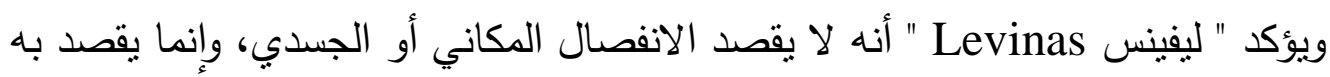

الاختلاف بيني وبين جاري، كما أن هذا الاختلاف لايفهم من ناحية العرق أو الجنس، أو أنه يتعلق بالنوع الإحتماعي، ولكنه انفصالًا حقيقيًا يضمن غيرية الآخر الذي يشاركني الحياة

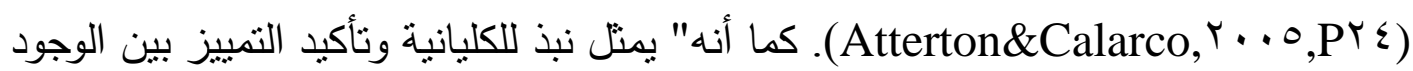




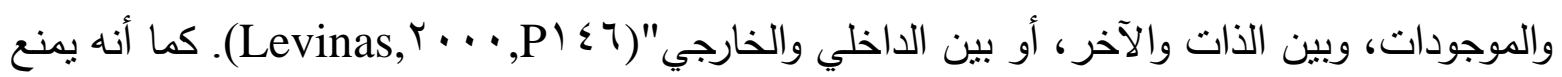

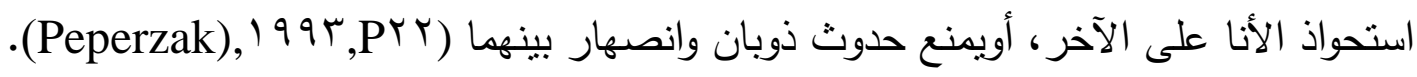

ويرمز هذا الإنفصال بين النفس والآخر عند " ليفينس"أيضًا إلى التعالي Transcendence

والسمو Height، والذي بدوره يجعل الآخر في مكانة أسمى من الأنا، وينتج عن هذا الانفصال تأكيد

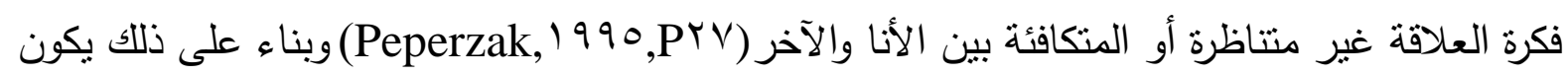
"الإنفصال خطوة حاسمة لتأسيس علاقة واقعية اتنقية وليست علاقة تمثنلية بين الأنا والآخر، فهو يمكننا

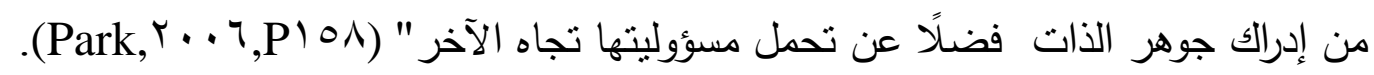
مما سبق يمكن القول، أنه على الرغم من سعي " ليفين" المستمر إلى تجاوز الوجود والأنطولوجيا

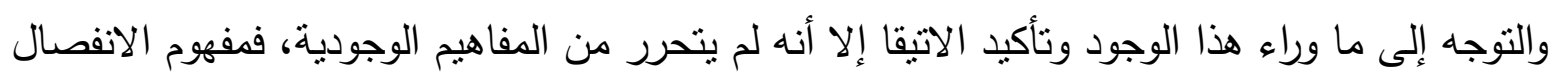

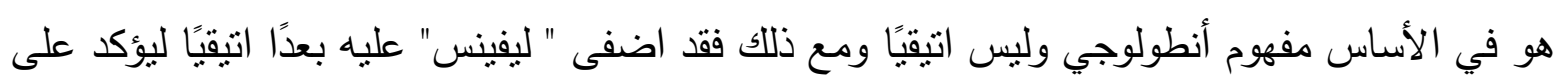

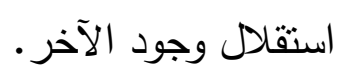

\section{ب- Infinite Responsibility For The Other المسؤولية اللانهائية نحو الآنزون}

بعد تأكيد وجود الآخر وأنه وجود حقيقي وأصيل، يتعين على الذات التخلي عن أنانيتها والتوجه

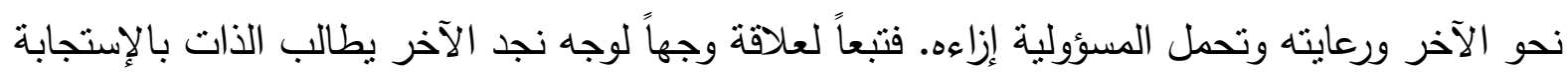
لنداءه من خلال ما يتجلى على وجهه من تعبيرات، فلغة الوجه لا تتمثل فى مجرد تحريم فعل القتل وإنما تتمثل في تقديم يد العون والمساعدة له.

يقول " ليفينس" " تلك النظرة تتوسل إلى وتطالبنى بالإستجابة له ولا يمكن الهروب من هذه

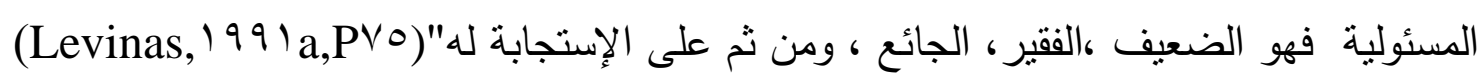

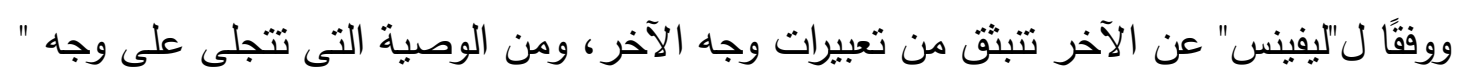

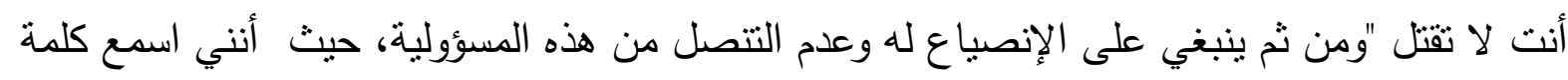
الله فى وجه الآخر ، إذ أننى ألتني الآخر من خلال الوجه، وهذا اللقاء يتجاوز الابستمولوجيا والمنطق،

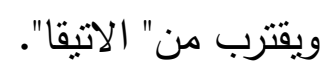

ولكي يدعم " ليفينس" آراءه حول المسؤولية يعود إلى التقاليد اليهودية والعبرية، إذ أنه يذهب إلى أن الأصل الإثتقاقى لكلاً من المسئولية Ahariout والآخر Aher واحد، ويستعين بما ورد في التوراه 
Torah لا تعني الحرية ، فاله يسأل قابيل أين أخوك ؟ (التكوين ^:؟)، وهذا معناه أن قابيل مسؤول عن مصير أخيه، حتى إذا كان يريد الفرار من هذه المسؤولية، فالمرء مسؤول عن أخيه وعن جاره

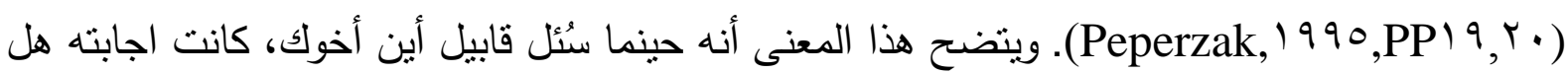
أنا حارس أخي، ... لا يجب نأخذ اجابة " قابيل" كما لو كانت سخرية من اله. أو لو كان طفل صغير ،

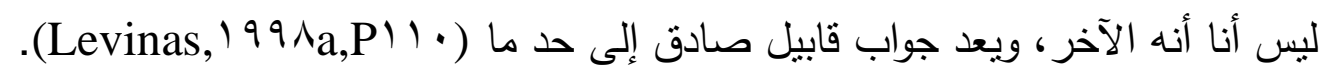

كذلك يعود " ليفينس" إلى عالم التلمود الليتواني " حاييم Haim" الذي طور مبدأ المسؤولية نحو الآخر ، والتي أثرت بشكل كبير عليه، فتبعًا ل " حاييم" الكون قد خلق لنا، وعلينا أن نحافظ على بقاء وإستمرار الوجود من خلال المسؤولية نحو الآخر، فالعدالة الإلهية تفرض علينا المسؤولية عن كل الآخرين، لأن الخوف من الله إنما هو الخوف على الآخر، كذللك انبثق مفهوم المسؤولية عنده من الوجه .(Levinas, 199 9 a,P 10V)

ويوضح " ليفينس Levinas" أن "هذه المسؤولية الثخصية نحو الآخر يؤكدها الله من خلال

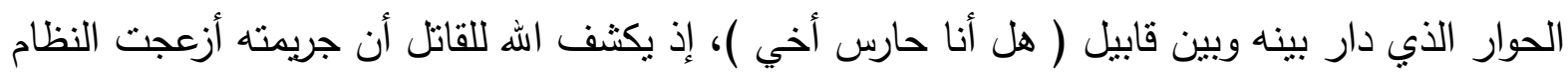
الطبيعي، لذلك يضع الكتاب المقس كلمة الطاعة والخضوع للآخر والمسؤولية التي ألقاها على عاتق

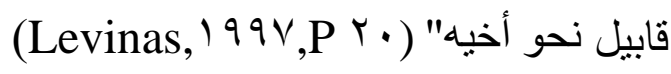
يؤكد الحكماء في التلمود،" أن المسؤولية تتجاوز الحرية، ففي تعليقاتهم على إحدى أيات الكتاب المقد" يسقطون واحدًا تلو الآخر" (لاويين: Vr: جr) ويشرحون أن هذا السقوط ناتج عن الثعور

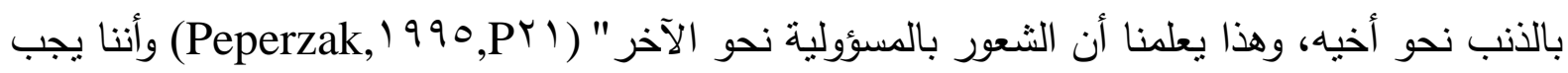

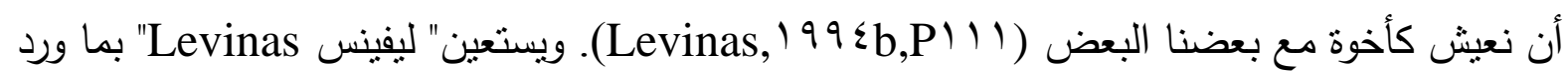

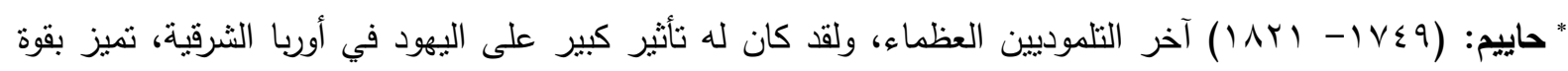

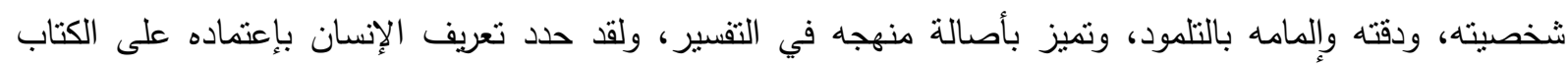

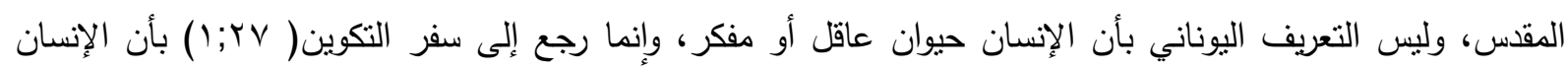

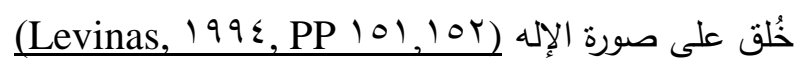




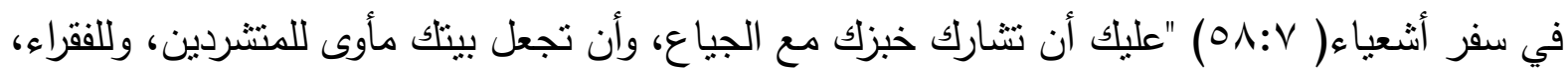

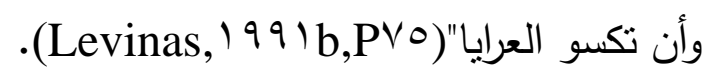

كل هذه النصوص السابقة نوضح مدى نأثر " ليفينس" بالتقاليد اليهودية، في مسألة المسؤولية عن الآخر . ويؤكد " ليفينس" أن "المسؤولية أمر جوهري، وأنها غير قابلة للإختزال، فلا يمكن التخلي عنها، إذ

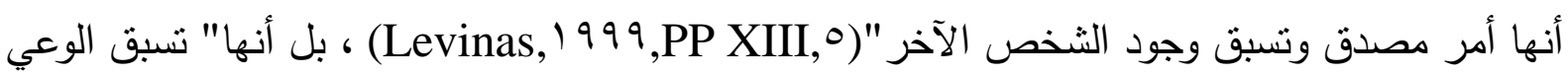
القصدي، وتسبق أي عقد أو اتفاق،وأنها توجد في الهيكل ما قبل الأنطولوجي Pre-Ontological، وقبل الهيكل الأساسي للغيرية"(Levinas, r. Pr,Por). كما يشير" ليفينس" أيضًا إلى أن" مسؤوليتي نحو الآخر هى التي تحدد هويتي كأنا أو كذات، وهذه

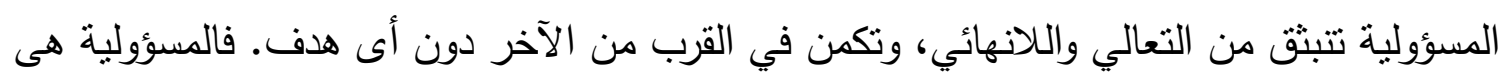

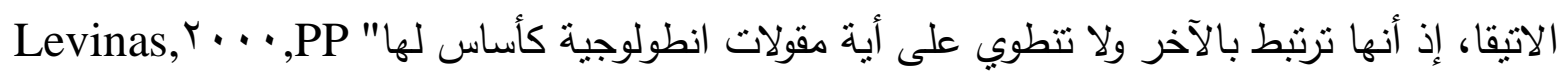
(190, • (1) فالمسؤولية هى قدر محتوم، فالإنسان مخول بممارسة المسؤولية حتى إذا كان لا يريد ذللك،

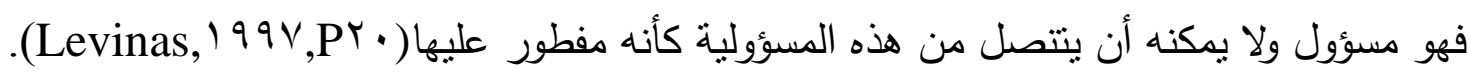
فأن أكون مسؤولاً عند " ليفينس" "إنما يعني أن أكون رهينة للآخر "Levinas 1997 a,Pᄉᄉ) أي

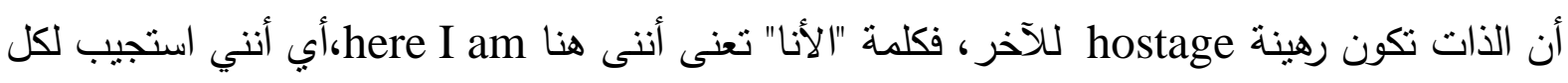
شىء لكل شخص. فالمسؤولية هنا ليست مسؤولية الأنا عن الأنا أو الذات عن نفسها ولكنها مسؤولية

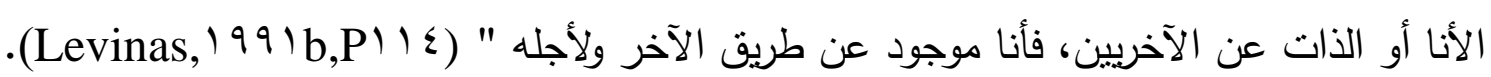
وهنا " تصبح المسؤولية عن الآخر أو الجار أمرًا حتميًا وضروريًا، يتردد صداها فيلا في نفس الأنا

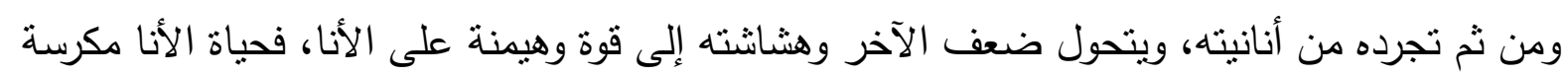

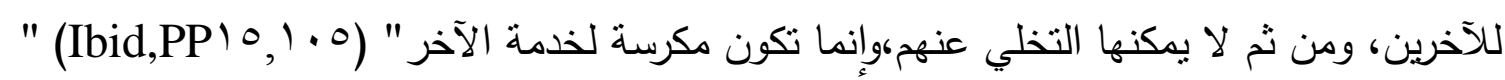

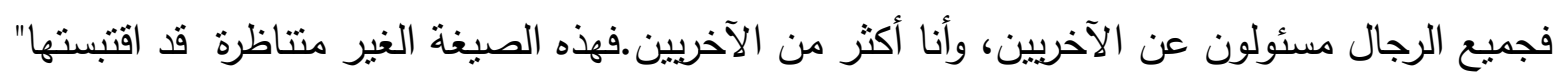

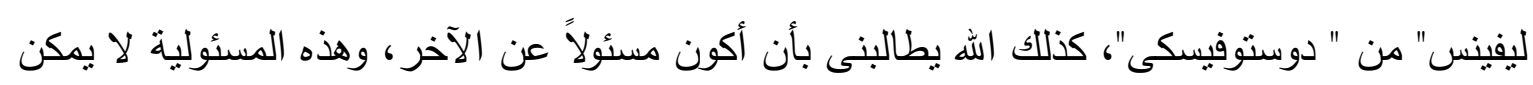

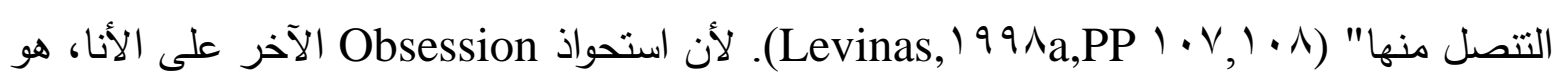


سمة من سمات المسؤولية التي لا ينبثق من الحرية، وإلا سيكون الاستحواذ مجرد وعي في حين أن

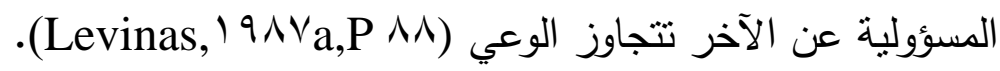

نخلص مما سبق: أن المسؤولية عند " ليفينس" مطلقة وغير مشروطة، وهى مسؤولية من الذات

تجاه الآخر ، أي أنها تقع على عاتق الذات دون الآخر ، كما أنها تسبق الوعي والحرية، بل تسبق جوهر

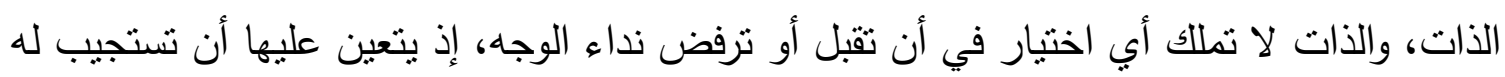
مباشرة وتتخلى عن أنانيتها. وفي حقيقة الأمر قد تؤدي آراء" ليفينس" عن المسؤولية إلى الثعور بالذنب

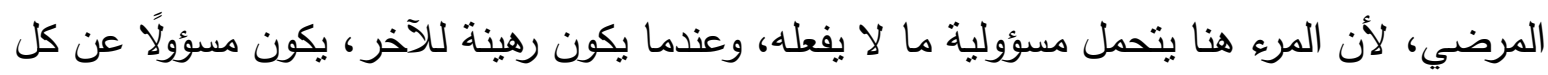

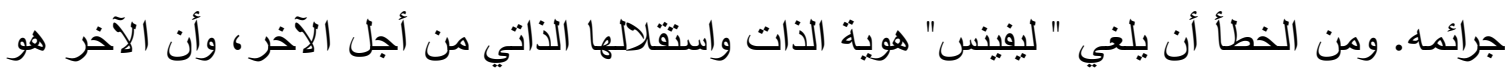

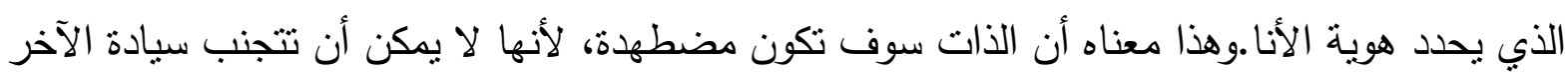

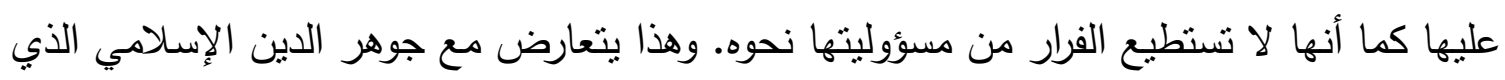
ينص على أن الإنسان حر ومسؤول فقط عن أفعاله.

كنلك تتعارض وجهة نظر" ليفين" مع آراء المعتزلة و إبيلارد فالعدل الإلهي يفترض أن يكون

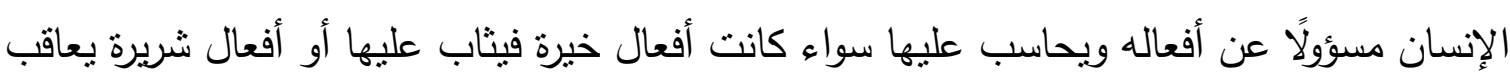
عليها، فالمسؤولية ينبغي أن تقترن بالحرية. كذلك من الضروري تضييق هذه الغيرية اللانهائية للآخر حتى يستقيم معنى الإلتزام والمسؤولية نحو الآخر بحيث تكون مسؤولية متماتلة ومتتاظرة بأن يكون الآخر أيضًا مسؤولاً عن الذات. كذلك لم يحدد لنا " ليفينس" من هو الآخر الذي يستحق أن نضحي من أجله،

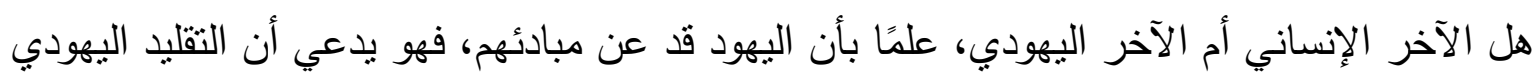
يدعو إلى المسؤولية عن الآخر والجار ، ولكن التساؤل الذي يفرض نفسه هنا هو هل إلتزم اليهود بهذه التعاليم أم أنهم خرجوا عنها وكانوا أكثر شعوب الأرض انتهاكًا لُحرمة الآخر وقتله وتعذيبه، أليس

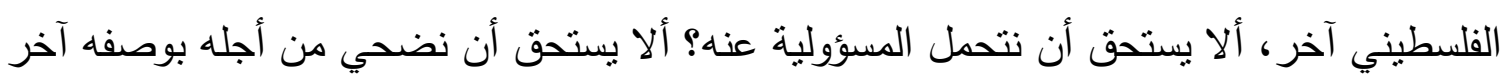
أيضًا؟!!. ولا يخفى على قارى" ليفينس" غياب حرية الاختيار أثناء تتاول " ليفين" للمسؤولية، ومن ثم فالذات مستعبدة لخدمة الآخر ، أنها عبودية واستبداد وليست مسؤولية . 
هذا الأمر يقودنا إلى " جان بول سارتر" المفكر الوجودي الفرنسي أيضًا الذي " " يربط بين الحرية

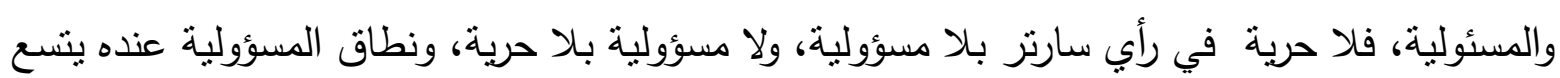

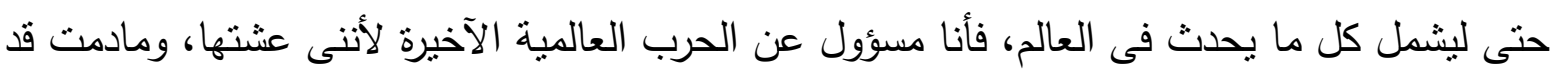
عشتها فقد إخترتها. والمسؤولية هنا هى مسؤولية الموقف الذى اصطنعه من الأحداث الجارية النى تقع

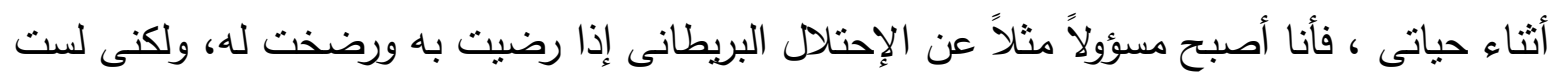

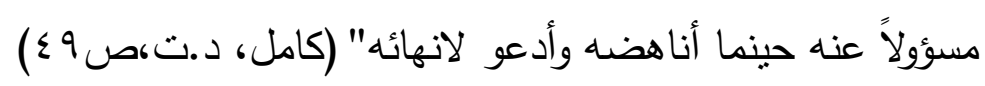
لقد قال" سارتر "' إن الإنسان قد حُكم عليه بأن يكون حُراً يحمل ثقل العالم كله على كتقبه، وأنه

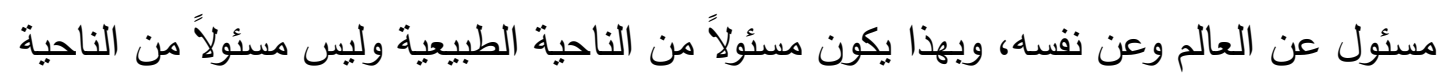

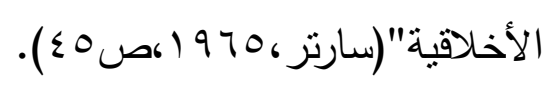

كما يشير"سارثر" إلى" أن الحرية ليست صفة مضافة أو خاصية من خصائص طبيعتي، أنها

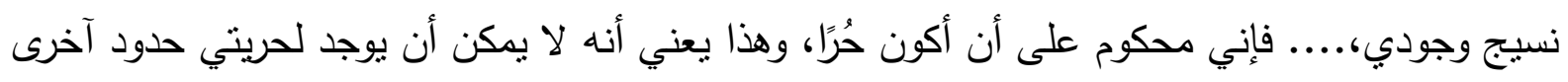

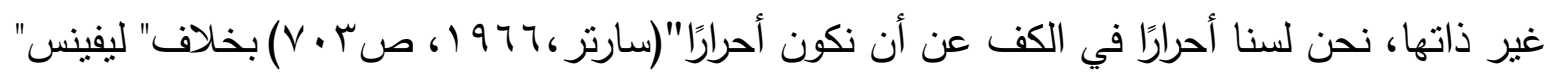

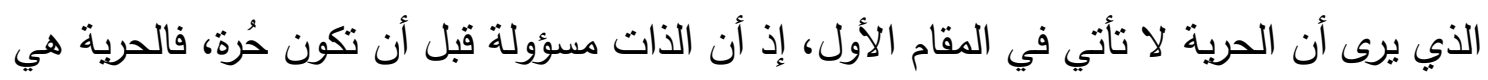

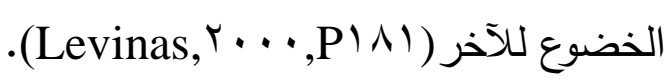

\section{ب-الخضوع والتبعية للآخر و المبادلة Heteronomy And Substitution}

ارتبط مفهوم الخضوع للآخر والمبادلة، بفكرة المسؤولية نحو الآخر والتي ترتبط ارتباطًا وثيقًا

بالوجه. فلقد انسمت المسؤولية بالخضوع المطلق للآخر ، وهذا الخضوع هو الذي يحدد هوية الذات،

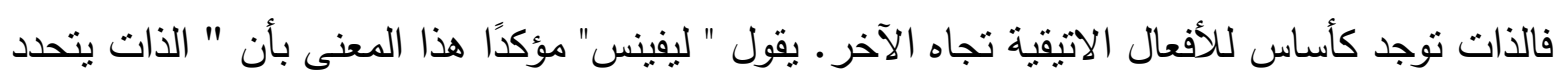

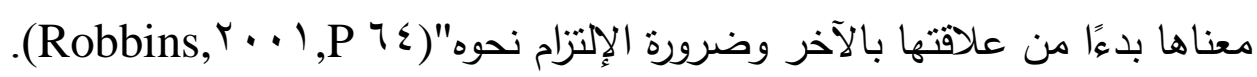
Hوفقًا ل" ليفينس Levinas" يعد وجودي كذات فردية رهينة للآخر Hostage Of The Other أثناء علاقتي معه، فالذات لا نأتي إلى حيز الوجود إلا من خلال علاقة وجهًا - لوجه والخضوع للآخر

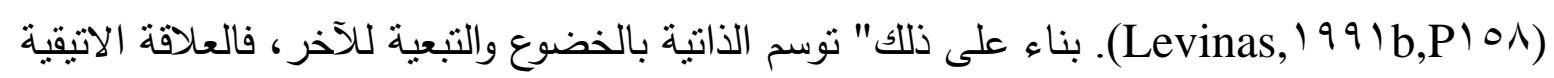
الإنسانية ليست مستقلة ولكنها علاقة خضوع للآخر ، تسودها المسؤولية والاستجابة للآخر ، ومن ثم فهو

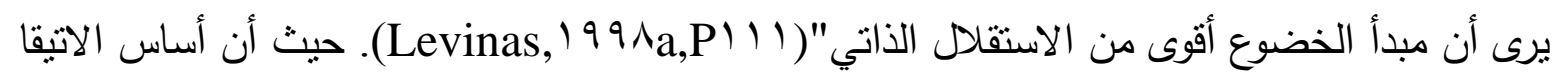


عique Ethiqu" ليفين" هو الاستجابة إلى الآخر ، وتحمل المسؤولية عنه، بخلاف كانط Kant الذي يذهب إلى أن الاستقلال الذاتي Autonomy هو أساس الأخلاق Morality (Skempton, r P I T,PY IV)

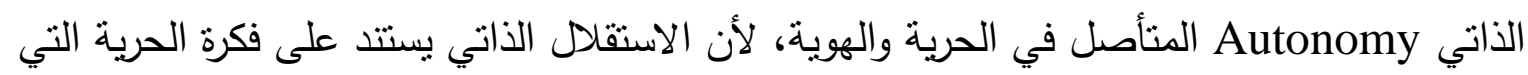
تختزل بدورها الآخر في النفس"(Levinas, I 9^va,P०^). وبذلك يكون الخضوع والتبعية للآخر Heteronomy هو الدافع الحقيقي وراء الفعل الاتيقي، والذي يتمنل في الرغبة في تحقيق سعادة الثخص الآخر،حيث تكون الرغبة الميتافيزيقية( اللانهائي) هى

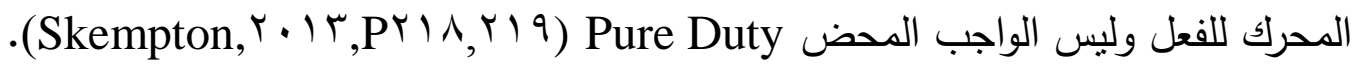
مما سبق يمكن القول، أن " ليفينس" يرفض الذاتية الأنطولوجية التي تؤكد استقلالية الذات ، ويقدم

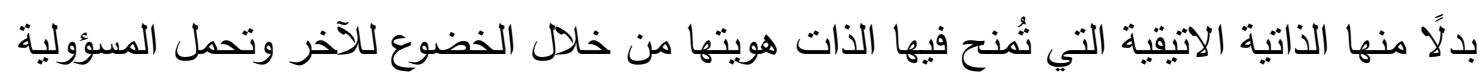
اللانهائية نحوه، وهو بذللك يخالف التقاليد الفلسفية الغربية التي في وقت ما، تدعو إلى الاستقلال الذاتي

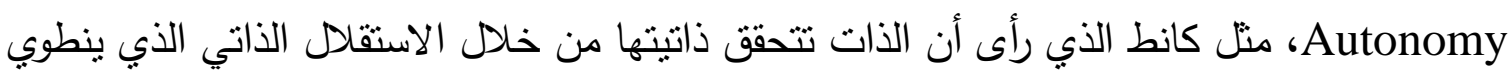
على حرية الإرادة. فعلى سبيل المثال قد أكد " كانط Kant "على الاستقلال الذاتي Autonomy والذي كان يعبر عنده عن الاختيار الأخلافي الصارم وهذا يعني قدرة الذات على صباغة القانون، والتحرر من أى قواعد

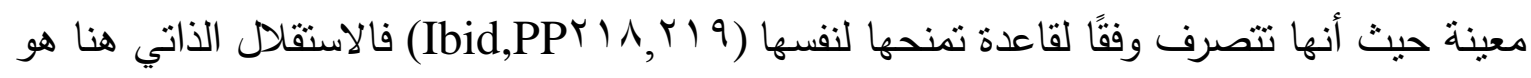
محور هام لأجل وصف القانون الأخلاقي Moral Law، إذ أنه يمثل شرطًا للقانون الأخلاقي وتأكيدًا

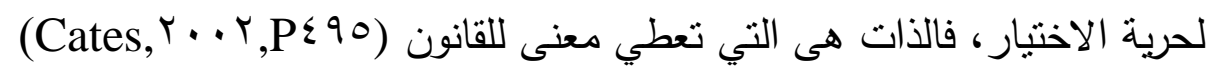
بناء على ما سبق، نجد أن " ليفينس" بخلاف "كانط" يسلب هوية الذات وفرديتها من أجل تأكيد الغيرية المطلقة للآخر ، بأن تكون رهينة للآخر وتخضع له، فالذاتية هى الخضوع، فلا وجود حقيقي للاذات، بخلاف الذات عند كانط التي تعد المشرع الحقيقي للقيم والمبادىء الأخلاقية. كما أن فلسفة " ليفينس" تدعو للعبودية وليس فيها حرية أو اختيار حقيقي للاتات في أن تتحمل المسؤولية عن الآخر أم تنتصل منها. 
ويقترن مفهوم الخضوع Heternomy للآخر عند " ليفينس" أيضًا بمفهوم المبادلة والتي تعني أن أكون بديلًا عن الآخر ، الذي يجب أن أقدم له الطعام والكساء، وتحمل

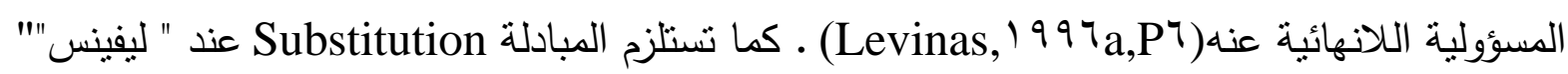
القرب من الآخر ، وأن أضع فكرة الغيرية في النفس، أو أن أضع ذاتي في محل الآخر "Levinas, 199^b,Prr) أنها" الخضوع المطلق للآخر ، وتحمل المسؤولية عنه، وكأن الأنا أن تقدم نفسها هدية للآخر ( Levinas, 199 ( b,P (90). وبناء على ذلك تكون" الذات الليفينسية مضيفة Host ورهينة Hostage للآخر في آن واحد، فهى مضيفة بمعنى الترحيب بالآخر كثرط أساسي للاتثقا، وهى رهينة من حيث فكرة اللانهائي التي تجعل الذات تستجيب للآخر وتتحمل المسؤولية عنه، وفي المبادلة يتم تحرر الذات من نفسها، فالذات رهينة ومحتجزة ومضطهة والآخر هو الذي يحررها من ذلك حين بربطها بالخير وتتحول من ذات مستحوذ

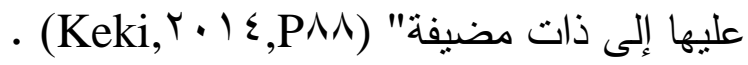
ويدعي "ليفينس" أن المبادلة لا تلغي فردانية الأنا وخصوصيته، بل أنها تؤكد فردانية كلًا من الأنا

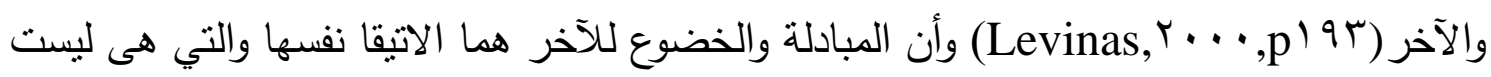

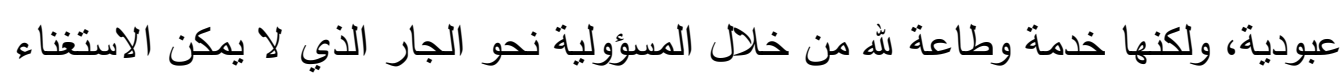
عنه (Levinas, $1994, \mathrm{P}^{2}$ (L) استتادًا لما سبق نستطيع القول أنه لا يوجد لقاء حقيقي بين الأنا والآخر عند " ليفينس"،بل يوجد

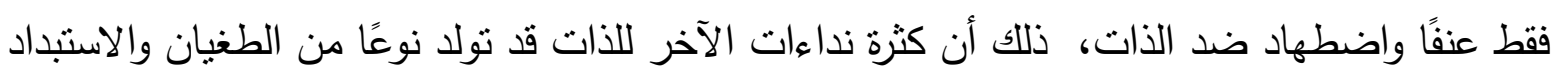
ضد الذات. يبدو أن " ليفين" أراد أن يتحرر من مركزية وهيمنة الذات في الفلسفة الغربية فوقع في مركزية وهيمنة واستحواذ الآخر على الذات، لكنه فنل في خلق حوار ولقاء حقيقي بينهما، فهما ليسوا على قدم المساواه معًا، فهناك السيد وهو الآخر، والعبد هو الذات. وهو بذللك يؤكد على العلاقة الغير

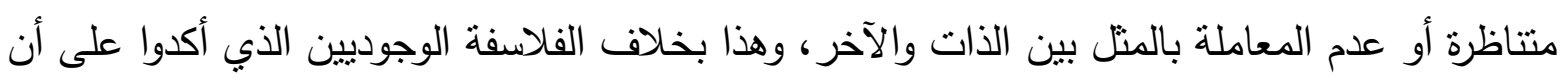
العلاقة بين الذات والآخر متماتلة مثل مارتن بوبر ـ كما سيتضح في السطور القادمة. ع - العلاقة غير المتناظرة Asymmetry بين الأنا والآخر:- 
لقد سلك كلاً من" بوبر Buber "و " ليفينس Levinas" طريقاً واحداً تمثل فى تجاوز الهدف الرئيسي للفلسفة منذ أفلاطون إلى هيدجر وهو (التساؤل عن الوجود والأنطولوجيا ) والإنصراف نحو الآخر ودراسة

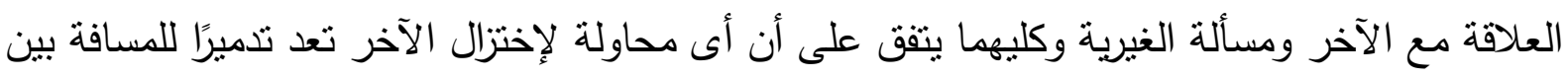
الذات والآخر وبالتالي تدميرًا للغيرية ـ كذلك كلاهما يؤكد على أن الاتيقا تعتمد على لقاء الأنا والآخر ،وليس على مبادىه القصدية الهوسيرلية، ويركزان على الإعتراف بالتعالي كجوهر حقيقى للعلاقة الاتقية، فكليهما يشرح العلاقة الاتيقية الحقة كنوع من الثوق والتطلع نحو الآخر ، والذي هو إعادة نوجيه للذات.

كذللك انبتقت أفكارهما ( بوبر ، ليفينس) " من المصادر الدينية لاسيما اليهودية والعبرية، حيث يحاولان احياء الحياة الدينية والتعمق فيها من خلال اهتمامهم بفكرة التعالي، كذلك يرفض كلاً منهما العلاقة أحادية الجانب التى تعتمد على المعرفة فقط، كنلك كلا منهما حاولا الإبتعاد عن الواقعية والمثالية التى تفرط فى الإهتمام والتركيز على المعرفة الموضوعية أو المفاهيم ، واهتم كلاهما بالعلاقة مع الآخر والاتيقا ومسئولية الأنا عن الآخر " Atterton\& Calarco\& .Friedman, ${ }^{r} \cdots$. ¿,PP $\mathrm{PP}^{\mathrm{r}}, \mathrm{r} \wedge$ )

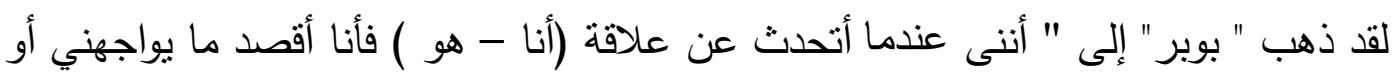
يقابلني كثىء - هو ، وعلى النقيض من ذلك عندما أقول ( أنا - أنت ) فإنني لا انظر أو اعتبر الآخر

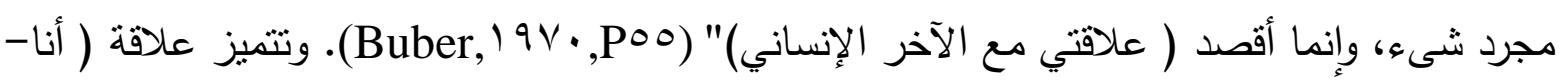

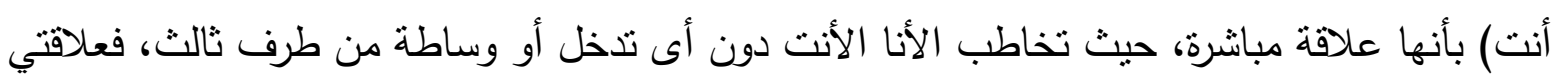
تكون اتيقية معه في المقام الأول، وليست علاقة ابستيمولوجية تعتمد على تراكم الحقائق والمفاهيم والمعارف (Stolle, Y . . l,Pl9) ومن هنا تبدأ الاتيقا التي تعتمد على الإنفتاح نحو الآخريين وضرورة

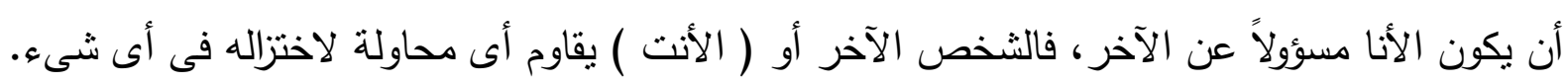

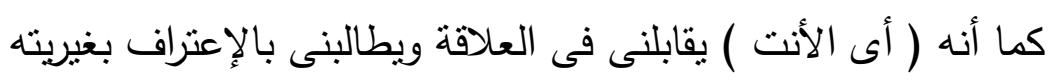

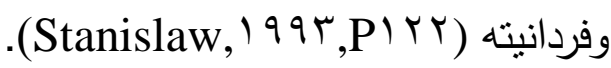
ويوضح" بوبر "أيضًا أن علاقة ( أنا - أنت ) هى علاقة مباشرة وتبادلية، أي إنفتاح نحو الآخر وقبول وإعتراف بغيريته ، وبأنه لا يمكن إختزاله إلى الأنا أو إلى تجربتى الخاصة، فالآخر أمر ضرورى إنى 
ومميز فى فلسفة " بوبر" وهو الذى يجعل الحوار مدكناً ، فالإنسان لا يكون إنساناً حققياً إلا بالحوار مع

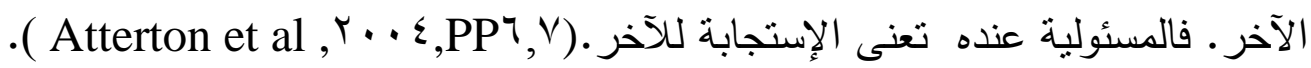

ولقد اتفق " ليفينس" مع " بوبر" في فهمه" للعلاقة مع الآخر كحوار Dialogue أو كنوع من المحادثة Conversation بين الأنا والآخر، فالتعبير الذي يتجلى على الوجه هو بمثابة اتصال يعلن فيه الآخر عن نفسه، وفي هذا الحوار يكون الآخر قادرًا على تقديم نفسه لي، كما أننا لا ندرك وجودنا إلا من لن خلال لقاءنا مع الآخر ، الذي لا يمكن اختزاله إلى المعرفة( Laforge, r...^,P^).

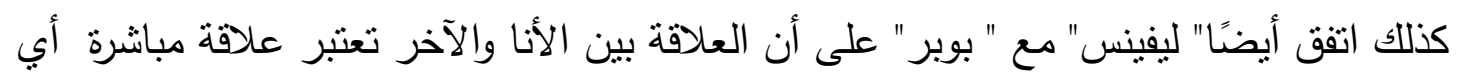

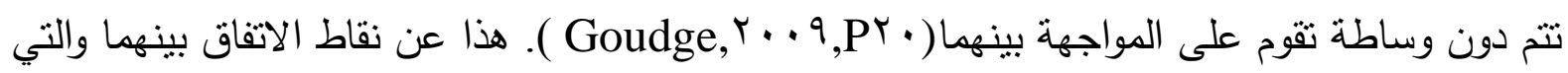

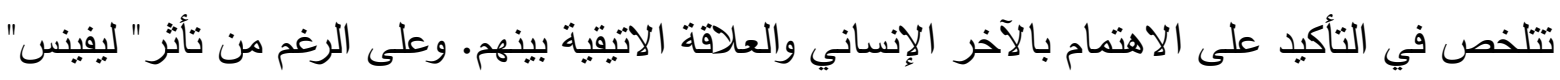

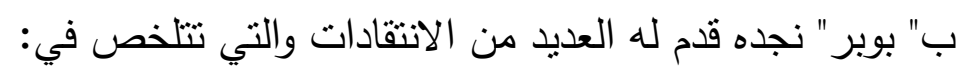
- أن" بوبر" يشير إلى مفهوم أو تصور (الأنا-أنت ) ليس كصداقة friendship، ولكن كزمالة أو مصاحبة comradeship، ففي الصداقة يمكنني أن أقترب من الآخر متخلياً عن حاجتي الأنانية، بينما فى الزمالة أقترب من الآخر من أجل العلاقة نفسها، كما أن العلاقة بين ( الأنا - الأنت ) ليست شكلاً

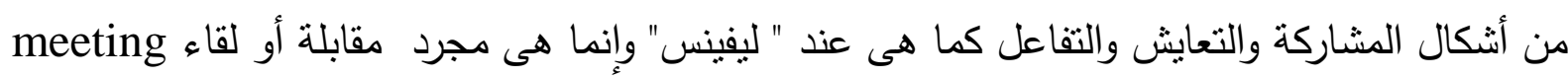
ذلك لأن الحوار يحدث بين اثتين كلاهما يعيشان معاً (Buber, $1991, P \vee 0)$. - يرفض " ليفينس" العلاقة المنماتلة ( المعاملة بالمنل بين الأنا والآخر ) بخلاف" بوبر" الذي أكد على أن علاقة ( أنا - أنت ) هى علاقة إجتماعية تحدث فى المجتمع وتفترض أن يكون كلاً من الأنا

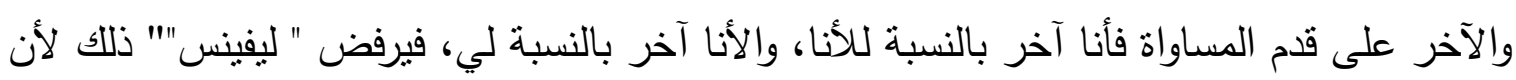

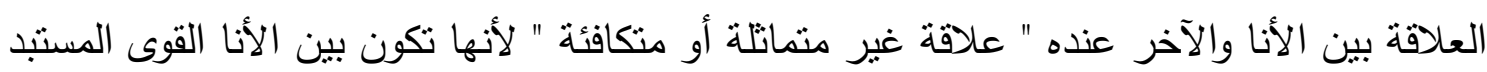
والآخر الضعيف الفقير ، فيظهر الآخر كثخص مدين لي يدعوني لتحمل المسؤولية نحوه، ومن ثم هناك تفاوت جذري بين الأنا والآخر، فالعلاقة مع الآخر نستتد على الأمر الذى اسمعه فى وجهه والذى يأمرنى

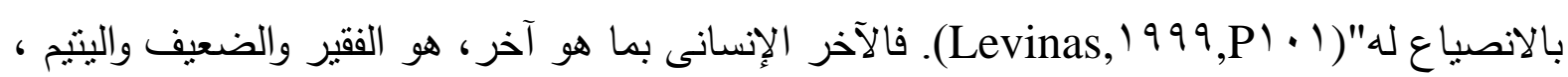




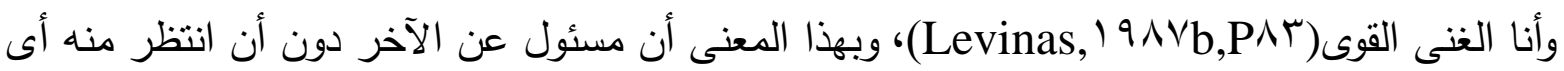
معاملة بالمتل (Levinas, 1910,P9^) "waiting for reciprocity). - كذلك يؤكد " ليفينس" الآخر يأتى إلى من بعد التعالي أو السمو a dimension of height "، ومن ثم فإن " ليفينس" يبدي قلقه وخوفه من علاقة ( أنا-أنت ) عند " بوبر "النى تختزل التعالِ والسمو الذى يأني من اله إلينا، وبالتالى يجعل اله على قدم المساواة معنا كثريك أو صديق Atterton et )

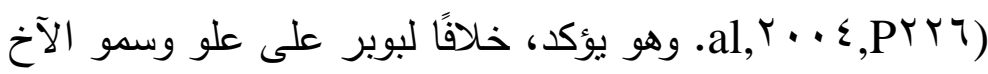
نظرًا لتجلي الله على وجه الآخر ، بينما " بوبر" في اعتقاد " ليفينس" قد اختزل التعالي والسمو بأنه جعل

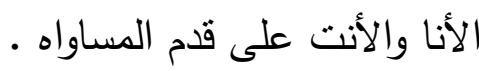

في ضوء ما سبق يمكن القول أن هناك تثابه قوي بين تصور " بوبر" لعلاقة ( أنا- أنت) وبين اهتمام "ليفينس" بالآخر الإنساني، هذا الاهتمام ناتج عن أزمة أوربا في ظل الحربين العالمينين وماشهدته

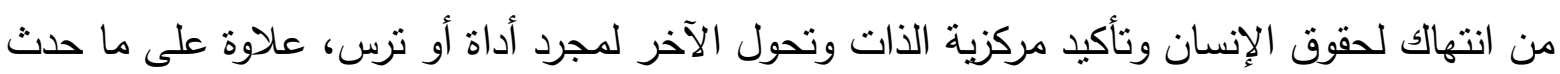
للايهود في هذه الفترة من قتل وإبادة، فإستجاب كلًا منهما لهذه الأزمة وانصب اهتمامهم بالموجود الإنساني والحوار معه ،والتأكيد على الجانب الاتيقي والإجنماعي للاين. التأكيد على وجود الآخر ( اليهودي) فحسب وتحمل المسؤولية عنه وعدم الإنتحواذ عليه.

وفي حقيقة الأمر يمكن القول أن هناك فلسفة للحوار عند "مارتن بوبر" بين الأنا والأنت حيث يخاطب كلًا منهما الآخر وكليهما على قدم المساواه ، بخلاف " ايمانويل ليفينس" ليس هناك في فلسفته حوار بين الأنا والآخر ، حيث أن الآخر دائمًا يأمر ويطلب من الأنا ، والأنا منلقي سلبي ينبغي أن

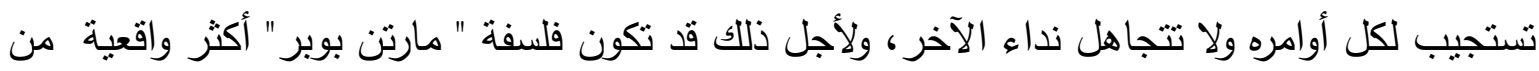
فلسفة " ليفينس" الذي يقضي على هوية الذات ويجعلها مسلوبة الحقوق. رابعًا: الموت من أجل الآخر Dying For The Other:يذهب " ليفينس" إلى أن التقاليد الفلسفية والدينية تفسر الموت على نحوين، إما" كمدخل إلى العدم، أو كنهج وطريقة جديدة إلى الوجود، إلا أنه يرى أن الموت هو استحالة لكل إمكانية

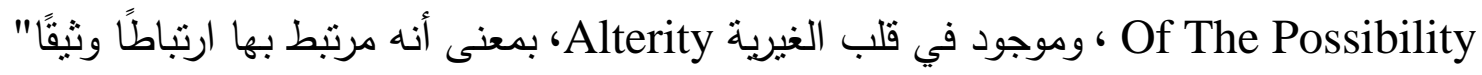


فالحياة الاجتماعية والموت يشتركان في تجربة اللقاء مع (Levinas, 1999,PYTO)

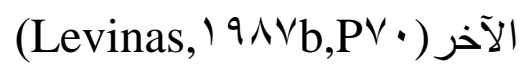

يقدم " ليفينس" نقدًا عنيفًا لتصور الموت عند " هيدجر" والذي هو مفهوم رئيسي عنده في فهم الوجود الإنساني، إذ يضفي على تصور الموت عمقًا انطولوجيًا، نظرًا لأنه مشكلة تخص الوجود نفسه،

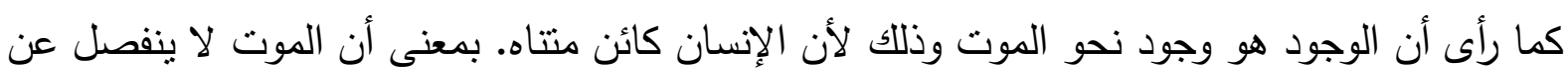
الإنسان، فهو الإمكانية القصوى للإنسان والتي تتضمن كل الإمكانيات الآخرى، وبالتالي لا ينظر إليه مينافيزيقًا كحقيقة موضوعية يمكن ملاحظتها،وانما ينظر إليه فينومينولوجيًا كثىء جلى وواضح (Demske, $19 \vee \cdot P \top)$. ويعرف " ليفينس" " الموت بأنه توقف السلوك، وتوقف الحركات التعبيرية والحركات الفيزيولوجية، أو العمليات الموكلة بالحركات التعبيرية الظاهرة والخفية...... فالموت هو الفجوة التي لا يمكن علاجها حيث تفقد كل الحركات البيولوجية كل تبعيتها في العلاقة بالتعبير أو المعنى، فالموت هو التحلل وعدم الإستجابة، فالثخص الذي يموت يصبح وجهه مجرد قناع Masque حيث تختفي تعبيراته، فتجربة الموت ليس موتي أنا، وإنما هو تجربة موت الثخص الآخر الذي يتجاوز العمليات البيولوجية منذ البداية، والذي يرتبط معي كثخص،..... فموت الآخر يؤثر في هويتي الثخصية كمسؤول عني (Levinas, $, \cdots, P P \prime), 1 r) "$

يقول" ليفينس" "أثناء لقائي مع الآخر ، فأنا أرى موت الآخر في وجهه، ولكني لا أرى موتي أنا،

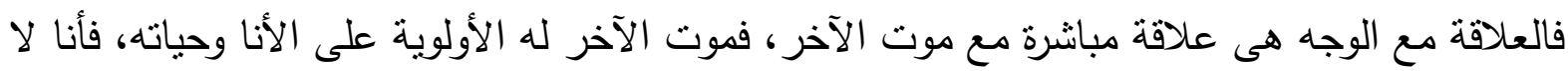
اتحدث عن الموت المبتذل العادي، بل اتحدث عن المرء الذي من الممكن أن يموت من أجل الآخر " (Levinas, 1999,P الموت يمكن أن نراه كمثال أو نموذج لعلاقة المرء مع الآخرين، فالعلاقة مع الموت مماتلة للعلاقة مع الآخر والتي هى علاقة مع شىء مجهول، وغير قابل للإدراك وغامضة، إنها علاقة مع من لا يأتي من داخله، ولكن مع الخارجي على نحو مطلق Absolutely Exterior

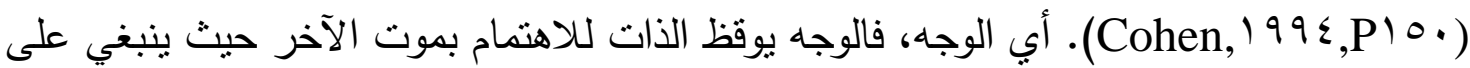

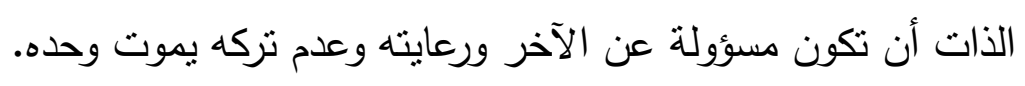


ويؤكد" ليفينس" أن " الموت هو موت الأثخاص الآخرين، بخلاف اتجاه الفلسفة المعاصرة التى

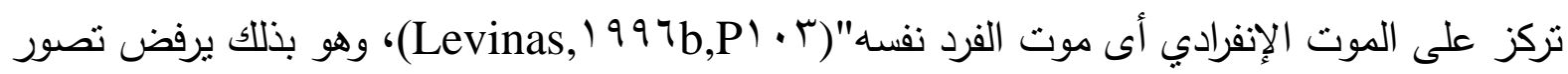

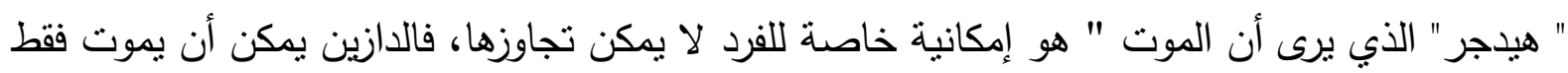

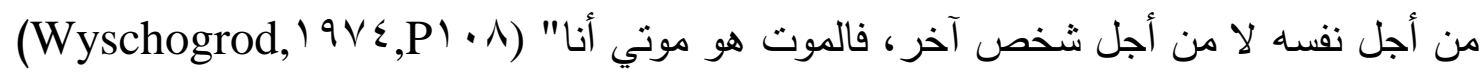
وبهذا يعبر" الموت عند " هيدجر" عن أقصى درجات الفردانية والخصوصية، فليس هناك أكثر من موت الفرد أو المرء ذاته، فالذات الإنسانية تتميز بالفردانية Individuated،وهى ذات حقة

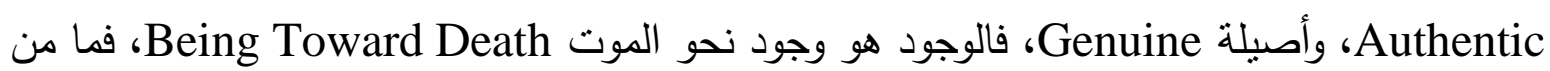

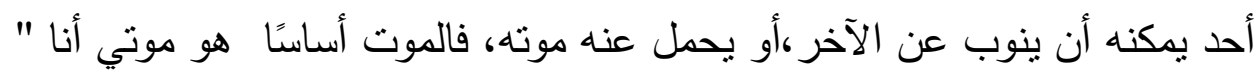
(Heidegger, 1997,pp ${ }^{\curlyvee \wedge 0}, r^{9} 9$ )

كما يرى" هيدجر"أيضًا أن الموت هو إمكانية الاستحالة المطلقة للازين Possibility Of The (Large, …^,P\乏) Absolute Impossibility Of Dasein

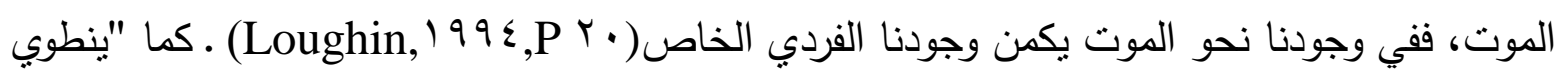
الموت عند " هيدجر" على قطع جميع العلاقات مع الآخرين، فهو إمكانية خاصة، فلا يمكن أن يكون إمكانية الوجود مع الآخر Possibility Of Being With- One Another، فقي الواقع أنا أموت بمفردي، أو في المنزل المحفوف بالآخرين، إلا أنني في الموت أموت وحدي أو بمفردي، ومن ثم كانت

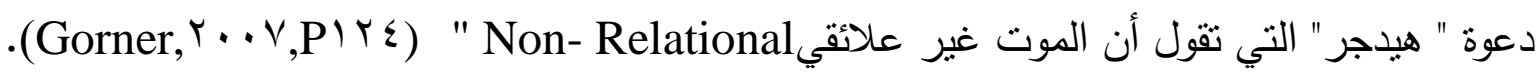
في الواقع يعتبر تحليل " هيدجر" للموت هو تحليلًا أنطولوجيًا نظرًا لأنه ينظر للموت بإعتباره شرط لإمكانية كل التفسيرات الآخرى، فالموت هو الوجود نحو الموت، ويفسره " هيدجر" كنهاية للازين، وأنه لم يعد هناك وجود في العالم، والموت تبعًا له هو موت الأنا، فلا أحد ينوب عني من الآنس الآخرين،

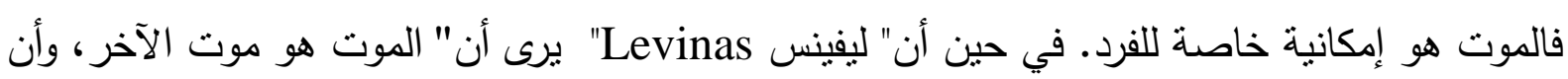

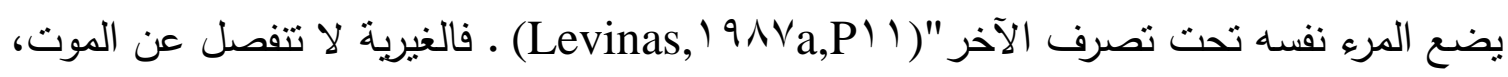
فالذات منورطة في موت الآخر .

ويرى" ليفينس" أن الوجود نحو الموت Being TO Ward Death عند " هيدجر، لا يمكن أن يؤدي إلى علاقة اتيقية مع الآخر، فتجربة أن الموت ليس موتي أنا، وإنما هو تجربة موت الثخص 
الآخر، ذلك الثخص الذي يتجاوز العمليات البيولوجية منذ البداية، والذي يرتبط معي كثخص ضعيف

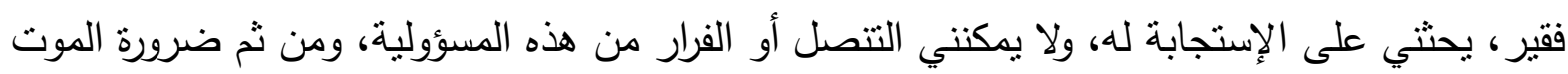

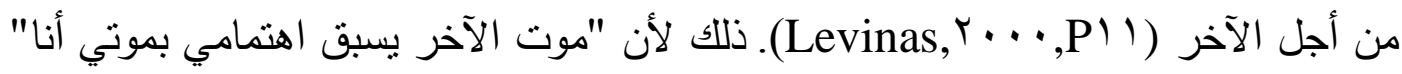
(Levinas, 199 हb,Prl)

كذلك يؤكد" ليفينس Levinas" أن تصور " هيدجر Heidegger" ليس حقيقيًا ذلك لأن الموت لا

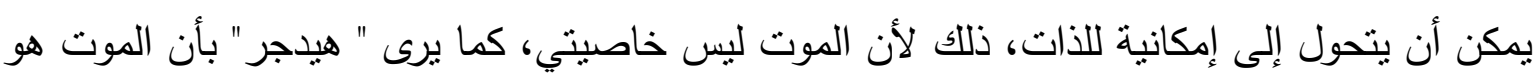

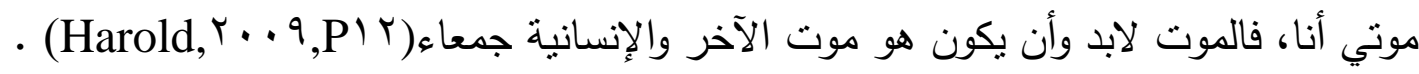

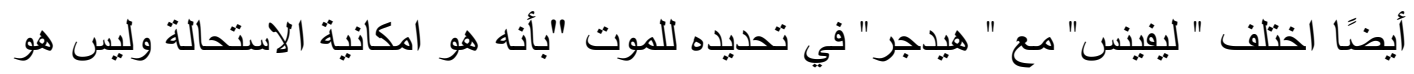

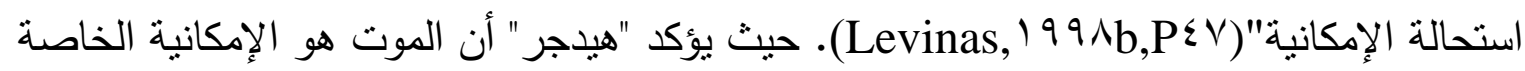
للازين ( إمكانية الإستحالة) فالموت غير قابل للإستبدال، فعلى الرغم من أننا نتخلى عن حياتتا من أجل الآخرين، إلا أننا لم نتخذ موت الآخرين بمعنى أن نموت بدلاً منهر .(Bunnin\&Yang\&Gu.Linyu, $, \vdash \cdots \wedge, P \backslash \leq \uparrow)$ بينما" ليفينس" يفهم الموت" كغيرية والتي تتعارض مع وجود الدازين، فهو إمكانية الاستحالة وهذه .

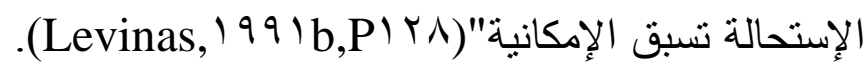

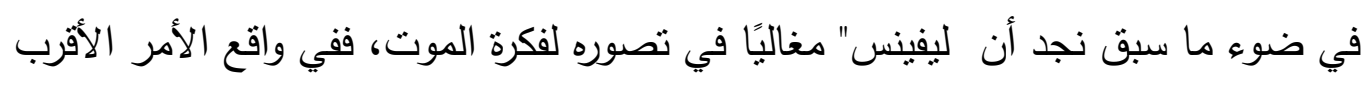

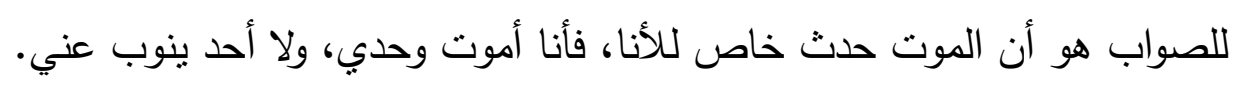


- - يحظى مفهوم الوجه بمكانة عظيمة عند " ليفينس" وله جانب مقس يحظر قتل الآخر ، فهذا الوجه هو مصدر الإلزام الاتيقي وهو الذي يحدد أسس التعامل مع الآخر وليس العقل ولا مقولات المنطق، ولم يقصد بالوجه ملامح الثخص أو سماته وإنما قصد به دلالة اتيقية تعبر عن الاحتياج للرعاية والعون والمساعدة أنه دعوة للمحبة وللسلام مع الآخر . - معظم المفاهيم الاتيقية عند" ليفينس" هى مفاهيم لاهوتية استقاها من الكتاب المقد العبري والتلمود، ففلسفته مشبعة بالتفسيرات اليهودية والثقاليد اليهودية، بمعنى أنه قد مزج يهوديته بفلسفته أي لهي التفكير في اليهودية فلسفيًا، والتفكير فلسفيًا باليهودية. - - إن تصور " ليفينس" للمسؤولية نحو الآخر يمنل عبنًا يقع على عاتق الأنا ويتولا عنها الظلم والطغيان والكراهية ، وربما تؤدي إلى الانتحار للتحرر من أعباء هذه المسؤولية حيث جعل " ليفين" الأنا مسؤولة عن الآخر بشكل مطلق ومسؤولة عن كل الجرائم التي برتكبها وهذه المسؤولية غير متتاظرة، كما أن تصور" ليفينس" غير ممكن ومستحيل تطبيقه لأن هناك في الواقع العديد من بن الآخرين الذين يعيشون معًا في العالم وليس علاقة ثنائية فحسب. - - هناك غياب تام لمعنى الحرية في فلسفة " ليفينس" فمن الطبيعي أن الحرية تنطوي على الاختيار

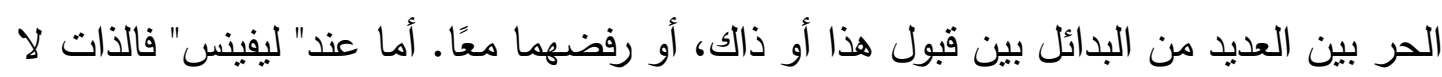
تمنلك أي اختيار وإنما يتعين عليها دائمًا الخضوع والاستسلام للآخر ولا سبيل للهروب من أوامره. - - أننا نلاحظ غياب فكرة الحوار الحقيقي عند" ليفينس"بين الأنا والآخر ، فالحوار يكون بين طرفين على قدم المساواه ينبادلان الحديث معًا متلما نجد عند " مارتن بوبر"أما" ليفينس" فقد جعل الآخر في منزلة أعلى حين جعله هو الذي يتحدث ويأمر وعلى الأنا الخضوع فقط فهى مجرد متلقي سلبي فحسب وهويتها تتحدد من خلال ما تقوم به من أفعال للآخر. - - هذا التصور الاتيقي عند " ليفينس" ينتج عنه غياب لقيم المحبة والاهتمام بالآخر وإبراز العنف والكراهية والطغيان. 
- يسعى" ليفينس" إلى إحياء وجهة النظر الكانتية القائلة بأن الأخلاق حتمية وضرورية وملزمة بثكل قاطع، إلا أن هذه الحتمية الضرورية هذه لا تتبثق من العقل متلما هو الحال عند " كانط" ، وإنما تتبثق من وجه الآخر والأمر الإلهي الذي يتجلى عليه ولا يرتبط الوجه بالايمان المعرفي وإنما يرتبط بالوحي الإلهي حيث يتم الكثف عن الله من خلال وجه الآخر والعلاقة الاتبقية. كما أنني لا أقابل الله كمحاور ولكن كآثر في الوجه،.بينما يبني " كانط" نظريته الأخلاقية من وجهة نظر ميتافيزيقية

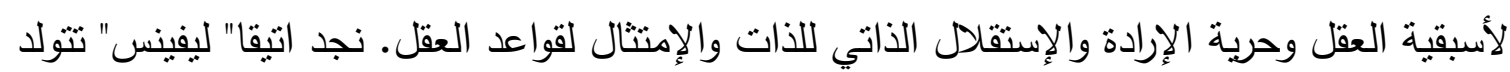
من التعبير المباشر والملموس للقتلى والجرحى والفقراء والمعوزين. والضعف والعجز الذي يشعر به

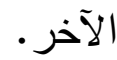

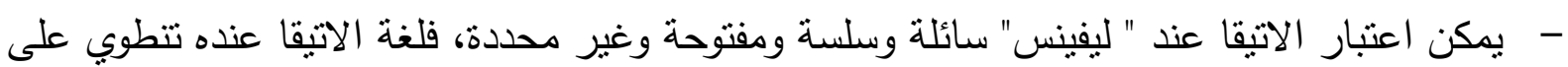

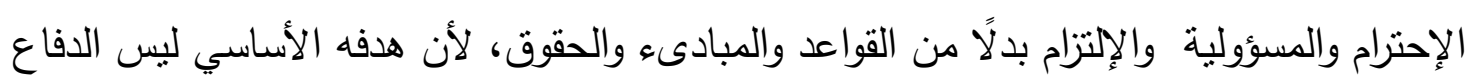
عن معايير معينة، وإنما تنمية الثعور بالمسؤولية والخضوع للآخر والإنصياع لأوامره.

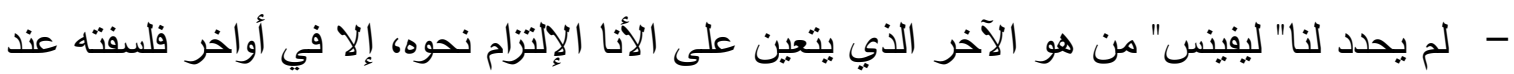
ولوج الفلسفة السياسية.

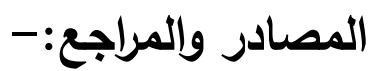 أولاً: المصادر :-}

1. Levinas, Emmanuel( (1910) Ethics and Infinity: Conversations with Phillipe Nemo. trans. R.A. Cohen. Pittsburgh: Duquesne University Press.

ץ. Levinas, Emmanuel ( $(9 \wedge \vee$ a) Collected Philosophical Papers, translated, Alphonso Lingis ,Martinus Nijhoff Publishers .

r. Levinas, Emmanuel ( $19 \wedge \vee \mathrm{b})$ Time and Other, translated by, Richard A .Cohen, Duquesne University, press.

Ł. Levinas, Emmanuel ( $\left(99\right.$ )a) Totality And Infinity, ${ }^{\sim}$ rd, trans, Alphonso Lingis, Kluwer Academic, Press. 
๑. Levinas, Emmanuel ( $1991 \mathrm{~b})$ Otherwise than Being: or Beyond Essence, $\boldsymbol{\varepsilon}_{\mathrm{rd}}$ trans. Alphonso Lingis. Kluwer Academic Publishers.

7. Levinas,Emmanuel(1994) Outside The Subject, trans, Michael B. Smith ,Stanford University Press.

$\vee$. Levinas, Emmanuel ( 199 a) Beyond The Verse Talmudic Reading and lectures, trans, Gory D. Mole, Indiana University Press.

^. Levinas, Emmanuel ( 199 \&b) In The Time of Nations, Trans, Michael B. smith, Indiana University Press.

१. Levinas, Emmanuel ( 199 \a) Proper Names, eds. Werner Hamcher \& David E. Wellbery. trans. Michael B. Smith. Stanford: Stanford University Press. 1. Levinas, Emmanuel (1997b) Basic Philosophical Writing, Trans, Adriaan .T. Peperzak \& Robert Bernasconi, and Simon Critchley, Indiana University Press. 11. Levinas, Emmanuel ( (99マ) difficult freedom "essays on Judaism " trans, Sean Hand, The Johns Hopkins University Press. Ir. Levinas Emmanuel ( $199 \wedge$ a) Entre Nous "Thinking Of The Other" trans, Michael B.Smith, Barbara Harshav, Columbia University Press. ir .Levinas, Emmanuel(199^b) of God Who Comes To Mind, trans, Bettina Bergo, Stanford ,Press. I . Levinas, Emmanuel( (१९9)Alterity And Transcendence, Trans, Michael B. Smith, 'in the United Kingdom, Landon. 10. Levinas,Emmanuel( $r \cdots$... God,Death ,And Time,trans, Bettina Bergo , Stanford University Press.

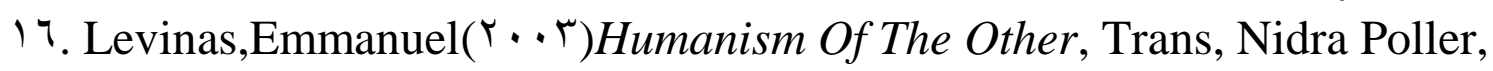
University Of Illinois Press. ثانيًا: المراجع العربية:-

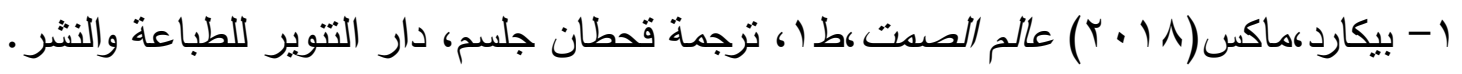


ץ- سارتز 6بول(970 970 ) عاصفة على العصر ،ط (، ترجمة مجاهد عبد المنعم مجاهد،دار الآداب لالنشر كبيروت.

r-سارتر ،بول(47 97 ( ) الوجود والعدم" بحث في الأنطولوجيا الظاهرتية" ،ط ( كترجمة عبد الرحمن بدوي،

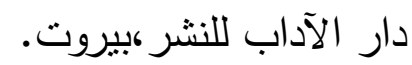

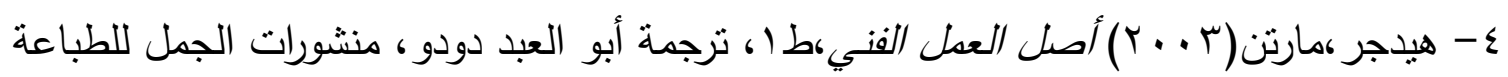
والنشر، ألمانيا.

ثالثًا: المراجع الأجنبية:-

1- Anderson, Ingrid Lisabeth ( $\uparrow \ldots 0)$ Making Ethics First Philosophy" Ethics And Suffering In The Work Of Emmanuel Levinas, Elie Wiese, And Richard Rubenstein, Boston University Press

$r$ - Atterton ,Peter, Calarco, Matthew , Friedman, Maurice $(r \ldots \varepsilon)$ Levinas \& Buber "Dialogue \& Difference, Duquesne University Press.

Bernasconi,Robert \& Wood David(19^^) The Provocation Of Levinas" Rethinking The Other", " Paradox Of Morality. "Interview With Levinas",

Routledge, London.

r- Buber, Martin( ( १४•) I \& Thou, Trans, Walter Kufmann, Morrison And Gibb Press.

¿- Buber, Martin( (9৭^) The Knowledge Of Man, A Philosophy Of The Interhuman, Trans Maurice Friedman, And Ronald Gregor, Prometheus Book, New York Press.

○- Bunnin ,Nicholas, Yang, Dachun, Gu ,Linyu $(\uparrow \cdots \wedge)$ Levinas Chinese And Western Perspectives, Blackwell Publishing.

7. Cohen, Richard ( 199 §) Elevations" The Height Of The Good In Rosenzweig And Levinas, University Of Chicago Press.

Demske,James M.( $9 \vee \cdot)$ Being,Man,And Death " A Key To Heidegger" Kentucky University Press.

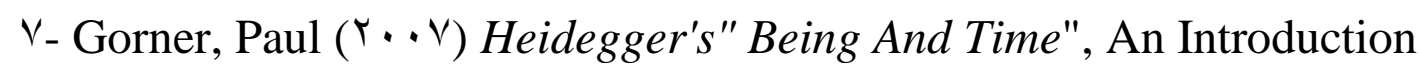
University Of Aberdeen, Combridge University Press. 


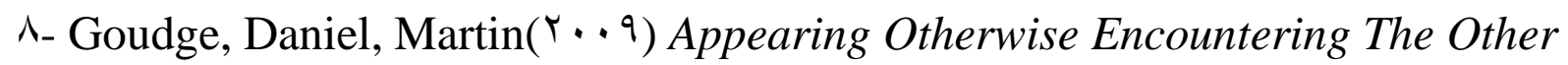
In Levinas, Stony Brook University.

१. Gunning, Meredith(। १९•) A Bout Face" Altered States Of Subjectivity In Levina"s, University Of Toronto

1.- Harold, Philip,J(Y ‥9) Prophetic Politics" Emmanuel Levinas And The Sanctification Of Suffering, Ohio University Press.

11 - Heidegger, Martin(1997) Being And Time, Trans, Joan Stambaugh, Albang State University Of New York Press.

I r- Katz, Claire ( $r \ldots r)$ Levinas, Judaism, And The Feminine" The Silent Footsteps Of Rebecca, Indiana University, Press

IT-Keki, Basak (Y.I乏) Nietzsche And Levinas On The Ethics Of Subjectivity, University Of Sussex, Press.

I \&- Laforage, Genevieve ( $(\cdots \wedge)$ The Importance Of Experience Art And Levinas, Stony Brook University Press.

10- Large, William ( $\left.{ }^{*} \cdots \wedge\right)$ Heidegger" Being And Time", An Edinburgh

Philosophical Guide, Edinburgh University Press.

17- Park, Wonbin(Y.. T) Emmanuel Levinas's Ethic Of The Other, Kenosis, And The Theodicy Questions, Boston University Press

IV-Peperzak Adriaan (1990) Ethics As First Philosophy "The Significance Of Emmanuel Levinas For Responsibility, Literature And Religion, Routledge ;

New York Press

1^- Peperzak, Adriaan( ( १९५) To The Other" An Introduction To The Philosophy Of Emmanuel Levinas, Purdue University, Indiana Press

19 -Purcell, Michael(Y.. T) Levinas And Theology cambridge university press

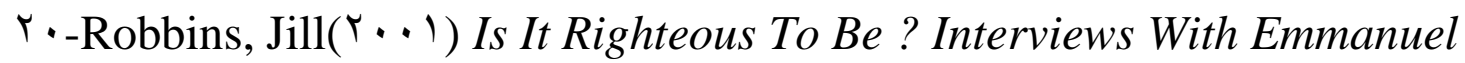

Levinas, Stanford University Press,

$\lceil$ )-Shepherd, Andrew ( $r+1 \varepsilon)$ The Gift Of The Other" Levinas, Derrida, And A Theology Of Hospitality, British Library

r r-Stolle, Jeffrey, James( $r$.. ) The Paradox Of Ethical Immediacy " Levinas And Kant" University Of Dregon Press.

rr-Wyschogrod,Edith(। $9 \vee \varepsilon)$ Emmanuel Levinas" The Problem Of Ethical Metaphysics, The Hague Press. 


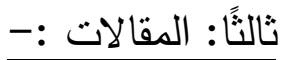

1- Cates, Darin Crawford ( r..r) The Fact Of Reason And The Face Of The Other" Autonomy, Constraint, And Rational Agency In Kant And Levinas, The Southern Journal Of Philosophy, Vol, XL.

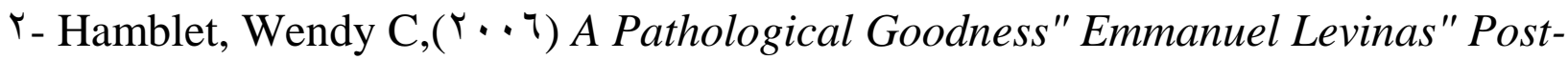
Holocaust Ethics, Minerva- An Internet Journal Of Philosophy, No 1.

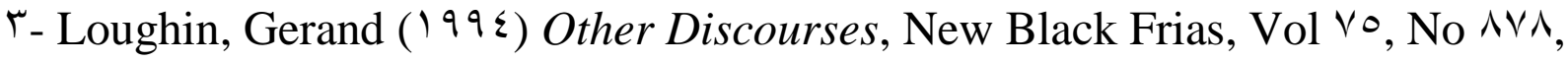
Jannurary

¿- Meir, Ephraim( $(\cdot) \cdot)$ Judaism And Philosophy" Each Other's Other In Levinas", Modern Judaism, Vol $r \cdot$, No ${ }^{r}$, October Press.

- - Moore Michael Edward(N.D) Meditations on The Face In The Middle Ages (With Levinas And Picard), ( Oxford University Press is collaborating with Jstor to digitize, preserve and extend access to Literature and Theology

7-Spencer, Mark (Y.Ir) Ethical Subjectivity In Levinas And Thomas Aquinas common Ground, State University Of New York at Buffalo, The Heythrop Journal V-Stanislaw, Kowalczyk, (199 ) Martin Buber Dialogic Personalism and the Christian-Judaistic Dialogue," Dialogue , and Humanism, vol. ${ }^{\Upsilon}$, no.l 


\title{
The concept of elegance in the the philosophy of Emmanuel levins
}

\section{Safa Ali}

\begin{abstract}
:-
Levinas Was Known As Philosopher Of Ethics Of Alterity And a philosopher of the face.

Levinas Has Remained his entire intellectual life calling The Ethics Is The First

Philosophy, this Ethics Is Depends on The Proximity Or Encounter The Human Other and having a face-to-face dialogue with him. taking the face as a Basis of his philosophy. where he describes the face as poverty, weakness and destitution, these expressions compel me to respond to it and take responsibility for him and die forhim.

Levinas Has assume The Face has Holiness, Where he sees that the infinite God is manifested on the face as a fleeting transgressor calling on me not to kill the other, saying "You shall not kill"

Any explicit call to love, care and concern for the other. Levines was influenced by Judaism and the encounter of God with Moses, peace be upon him, face-to-face, to emphasize the Holiness of the face and the encounter with the other and the importance of this Encountering.

Levinas has depended on he Jewish tradition to formulate his Ethics, after the failure of morality in his view on the events of the Holocaust. He rejected all moral doctrines and formulated Ethics of the face.
\end{abstract}

KeyWords: The Face, The Infinity,Responsibility,Separation, , Heteronomy And Substitution. 